\title{
Providing Biodiversity and Ecosystem Services through Common Pool Resource Management as Hybrid Institution: On Eco-Net Advances and Payments for ESS in Cultural Landscapes
}

\author{
Ernst-August Nuppenau \\ Department of Agricultural Policy and Market Analysis, Justus-Liebig-University, Giessen, Germany \\ Email: ernst-august.nuppenau@agrar.uni-giessen.de
}

How to cite this paper: Nuppenau, E.-A. (2017) Providing Biodiversity and Ecosystem Services through Common Pool Resource Management as Hybrid Institution: On Eco-Net Advances and Payments for ESS in Cultural Landscapes. Natural Resources, 8, 478-512.

https://doi.org/10.4236/nr.2017.87031

Received: April 27, 2017

Accepted: July 28, 2017

Published: July 31, 2017

Copyright $\odot 2017$ by author and Scientific Research Publishing Inc. This work is licensed under the Creative Commons Attribution International License (CC BY 4.0).

http://creativecommons.org/licenses/by/4.0/

\begin{abstract}
In many rural areas the management of natural resources is confronted with the tragedy of the common problem; not only historically but also in modern times. Especially where biodiversity loss appears and ecosystem services (ESS) decline, the lack of public management might be related to inappropriate institutional setups. Two distinct directions of thought prevail on the subject. On one hand, proponents of property rights and minimal state intervention eagerly analyse the feat of modern institutions and view private property and payments for ecosystem services (PES) as solution. On the other hand, common pool resource management (CPM) has regained interest because nature is not a straight commodity and cooperation in ESS provision is needed (partly also to facilitate PES). In this paper, the two aspects are combined in a hybrid institution. We suggest a new way of approaching institutional questions in ESS provision as synthesis of private and publically controlled ESS provision. It is contemplated as ESS governance of local eco-nets given the potential for inclusion of public management. In principle, the result is a controlled framework of land sharing between farm land (private ownership) and communally managed land (public ownership). Some land is devoted to hedges, wetlands, etc. Land is an immobile resource and can be used for EESs based on planned species prevalence, whereas communities compete also for labour which can move (or not). Governance is acting in competing constituencies and is a mean to control the regulating entities (public ESS management). At a meta-level we combine the need for public management with advantages of a competitive neo-classical framework. This contribution to CPM investigates a model of a group whose well-being is based on ESS provision in
\end{abstract}


a cultural landscape. By statutory regulations, land (field margins), is extracted from farms for ESS; in particular a leader (called reeve) guides farmers. Two institutions are compared: (1) labour in public land for ESS based farming (i.e. it is controlled by public authority), or (2) it can migrate seeking higher rents in neighbouring communities.

\section{Keywords}

Common Property Management, Competition between Communities, ESS Regulations

\section{Introduction}

\subsection{Theme}

The management of common pool resources (CPR) in cultural landscapes, as connected to farm communities, has gained new attention among practitioners and scientists in many countries, both developed and less-developed. Especially, an intensified debate on institutional issues related to commons has drawn attention on failures with more individualized provisions of ecosystem services (ESS), as well as corresponding payment schemes (payments for ecosystem services PES) in which property rights are primarily with farmers [1]. So property rights and governance are pertinent issues. We see an acknowledgement of needs for imposed cooperation among farmers, especially for spatial coordination [2]. Spatial coordination identification of ESS shall recognize neighbourhood effects and eventually address whole eco-nets. Furthermore, questions of transaction costs in conjunction with allocations of land for spatial priorities in efficient biodiversity provision (BD) are on the agenda [3]. New approaches for governing nature and $\mathrm{BD}$ as well as active public management are also on the same agenda. Issues are moreover studied under the auspices of minimizing transaction costs and avoidance of rent-seeking [4]. Apparently, both pure markets solutions and regulatory approaches show limitations, so a hybrid solution is needed. Another important issue is the need to find modes of achieving long-term cooperation (commitment), trust, and self-interest in ESS itself and amongst farmers.

Because the promise for cooperation shall reduce costs in governing ESS, we need an increase in likelihood of improved BD and assurance of ESS delivery by public management (beyond individual farm interest in PES and BD, i.e. just for cash). A reliable commitment ought to be imbedded in an institutional frame assuring physical appearance of $\mathrm{BD}$, regulations on provision and shared payments. In this regard, detailed delivery concepts like " $B D$ through eco-nets" have been proposed, which are driven by ecology rather than farm interest (ecoagriculture: [5]). This includes the assignment of specific tasks to farmers, first (provision necessarily relies on an ecologically efficient net structure and ESSs 
are a joint product) and payment, second (as sufficient condition) [6]. Accomplishment of such net-structures in a landscape for ESS implies that an efficient $\mathrm{BD}$ provision and management occurs; not a diffuse one. Provision should be based on appropriate assignments of site specific tasks (goal oriented and jobs to be done for ESS, stating rules, etc.).

For farmers CPR means conceding of property rights that might even include statutory regulations. (Note: an emphasis is frequently on ESS delivery as synergies between land parcels and habitats by using deliberate interactions of "net design" [7]). Only, in such cases, ESS can benefit communities as public goods, as well as the public acts as a provider of ESS; but also only under the condition of a "good" governance (at minimal cost here with coordination) where might be acceptance of regulations. Many costs are private for farms; especially having less land is an issue. I.e. since a landscape must be addressed by design, a community of farmers (living in the landscape) should have chances to see advantages through plans worked out for the public good. We foresee joint commitments and delivery. Joint delivery connotes cooperation, coordination and synergies; this should prevail between all the farms-land parcels, fields, biotopes etc.-(for reference to traditional way [8]). Showing how to log such findings and to include ecological needs in logics of cooperation is the aim of this article. I think governing commons is an explicit task for management and it should be an important topic in BD and ESS provision; yet it is a necessary query not yet solved. We will see that it is also an institutional problem on rights. And it is suggest how to design a hybrid institution combining Payments for ES with control (governance) elements. Assuring participation and getting site specific regulations, is necessary for the establishment of ESS in a landscape.

\subsection{Institutions}

However, the above arguments have to be presented into a deeper discussion on institutions. More market (invisible hand) oriented proponents for ESS management suggest institutions which are mainly based on private rights. (Proponents see keys for successful ESS provision in priced payments similar to commodity supply). Here ESSs are separable and should be based on specific incentives individually chosen by farmers. Economic oriented scholars see institutions working as "carrots" and "sticks". Proponents of more complex PES, particularly addressing cooperation, argue for solutions with bonus payments (for an agglomeration bonus suggestion see [9] and spatial coordination is secondary [10]. In regards to solving cooperation, it is believed that an appropriate design (giving extra payments if neighbours collaborate) is sufficient to provide the right incentives (carrots) at low costs. But, what happens if neighbours are not committed?

In contrast, more community (i.e. public control) oriented researchers argue for common pool resource management CPR on the basis of statutory regulations [11], including direct controls and indirect interferences in land use (as 
sticks). For instance by: (i) setting guidelines and prescribing conservation on farm land (indirectly for ESS), (ii) requesting land to be set aside for field margins in eco-nets (directly, as minimal support for ESS) and (iii) launching actions on active $\mathrm{BD}$ provision (such as labouring for conservation of biotopes, etc.), a public authority (management) should seek to get mutual commitments from farmers for ESS provision. Then, importantly, some (maybe not all) property rights for management of land shift to the public (on need for public management see [12]). As Jones [13] has argued recently, nature conservation should be statutory (obligatory; not voluntary oriented; rights and payment are less important); this, because ESSs benefit society as a whole. A change of behaviour for the better (more ESS based on sound nature, compared to a nature purely based on monetary incentives) seems to be a matter of authority; but not completely. Community involvement may be expected because regulations as part of accepted practices can force neighbours to do similar things (as self) without always checking costs, society rules for personal contributions outside official regulations are also needed. Then the difficulty lies within finding, what is the equilibrium point between a person's own willingness to do something for nature and prospects towards others to contribute? If ESS provision requests action from all farmers, what are rights and rules? An immediate question is whether PES and governance are contrasting approaches which exclude each other or not? Or are they complementary? A query is whether we have option in terms of a third way of (co)-operating. Can we expose a way in between, which borrows good parts and rejects bad of state, respectively? I.e. can market and state rule jointly in ESS provision? Such query is not easy to answer due to details (beyond seemingly simple alternatives).

In this paper I suggest a new way of approaching the institutional question in ESS provision, especially as joint concept of local governance, i.e. paralleled public management of the common ESS and payment for ESS. As well as we will see an inclusion of a secondary component: competition between managers at sub-regional level. We will talk about competition of constituencies (Leviathans) as means to control regulating units [14]. This can be achieved by the outlining of an ancillary market, for example, labour movement along returns, which will be shown. It is a hybrid institution where there are some elements under public control (mostly land), but with free labour movement between communities. It is investigated with regards to emerging questions on needs for public management and control in ESS provision (as mentioned, i.e. who mandates farmers to care for BD by statutory regulations and control [15]). This is not really new. For instance, in traditional societies, common resource management and land use institutions have already included public regulations (traditionally addressing soil fertility, pest control, pollination, etc., for example by rotation, diversity, wetlands, etc.). Today, we see similar ideas for sustaining landscapes and socioecological systems and common rules. This has been advanced by Brunckhorst [16], but needs further attention. 


\subsection{Common Pool Resource Management in Case of BD Provision for ESS}

Though, such suggestion has its "price": especially the involvement of active government planning. Taming of public managers (as planners: Leviathans) comes into the debate. As suggested by Rauscher [17], it can be done through labour markets (in modern terms: competition as an institution for controlling rent-seeking). The problem of balancing cost and benefits for institutions has already been given attention, for instance as design for complex right structures [18]. As generalization these authors asked for interactions between markets and governance. Yet we can borrow from the ideas systematically. Looking at generalized developments in public economics the idea is: "regulatory rules for notover-taxing actors (as burden avoidance)..." It can be transferred. In fact, community management should be capable of charging especially strong beneficiaries (asking for royalties) and using money for provision of public goods; here ESS. Yet, fiscal inquiries are a special issue in terms of user-and-public-involvement in ESSs. Such thoughts relate to an institutional design of competition between communities [19], because strongly effected farmers (labour) threaten to move. At the one hand this is "natural". At the other hand institution must involve participation (no moving and being willing to comply with regulations) and being fine with compensation (PES), since it might be a query for management (to migrate or stay a group member).

In the article we offer a transfer of the idea of competition between constituencies (management units) from public policy to CPR for ESS provision in landscapes. It is the intention of the paper to show how one can apply findings about alternatives in regulation of public good provision to ESS provision based on $\mathrm{BD}$. The suggestion (modelling) is based on contracts and rules of conduct between farmers and managers (presumably being ecologists). This has to be done at group level. We want to open-up a discussion about rules that guarantee community provision of $\mathrm{BD}$ (as habitats) and access to ecologically linked lands. Land is initially owned privately, but some of the land such as eco-nets, is managed by groups. Rights to acquire land are assigned to management for habitats. Hitherto we want to enforce a regulatory body to minimize power and rentseeking. This goal can be reached by allowing competition in terms of setting limits in contributions for public delivery (migration in case of [20] and [21]; labour for land use). Developing biologically active ES and ES Services linked to $\mathrm{BD}$ is considered a key measure of creating livelihoods in rural regions that strongly depend on nature. Seeking to reform ESS provision is pertinent because current CPR management systems seem to fail to get binding regulations and ESS visibility (as necessary conditions to get support for resource conservation). We link the idea on provision of commons either by a joint, private, or market mechanism that is expressed in a mix of rights on farmers' land, labour and authority. As a right for public management, some land shall be blocked for (transferred to) nature conservation reasons. Farmers may do so voluntarily be- 
cause they expect regulations and there is the scope to influence management by committed vs. not committed labour, which is out of the control of public management.

\section{Objective of the Study}

The general objective of the article is to show that CPR management for ESS provision, which is based on land-set-aside (habitat provision) as common and labour (working for nature) as public work, improve welfare of communities. The approach is a theoretical outline of how interaction of individual objective functions can serve to strive for ESS. It shows how forming of public preferences (power in political economy terms) is feasible by making reference to individual decision making. Based on a theory of collective bargaining and competition between managing units, a balance is reached that shows benefits from ESS. The specific objective is to analyse impacts of gradual changes in institutional setups of groups. This theoretical work shall help building a platform for the investigation of new approaches in common-pool-resource management CPR to combat resource degradation in communities having strong needs for ESS.

The article is organized in five sections. (1) We will discuss biological aspects of species occurrence and land allocation in a community as it opens scope for designing regulations. (2) We will discuss implications for land allocation and show how to exemplify gains from ESS at the community level. (3) We will introduce political economy modelling for bargaining and getting a community objective function. Thereby, a specific, goal oriented function is pursued by a partial manager of the common property (ESS and BD) and management is entitled with regulator power to acquire land from farmers. (4) Since some labour (also under control of the manager) shall further improve the status of nature, labour (as a problem of shared allocation) will be investigated further. (5) We will then investigate impacts of different labour arrangements on the basis of sub-regional control, but only as competition between two communities.

\section{Outline and Study Design}

\subsection{Frame}

We start with necessary design aspects in order to achieve a formal approach on the functioning of public management for ESS provision in a cultural landscape (hereby the focus is on habitat provision). To rationalise the thoughts on (i) the provision of BD by a community as public management, (ii) delineating needed mechanism, (iii) finding public management rules, (iv) envisaging responsibility, correspondingly, etc., we suggest applying a model where farmers, in principle, have private ownership of land. Nevertheless, the common property manager shall enforce (v) setting aside of land for ecological reasons. This is done (vi) in an ecological main structure EMS [22] or eco-net in modern terms). I.e. with regards to EMS, full land user rights are no longer with farmers. The public re- 
quests an ES oriented land management that costs farmers reduced access to land, though equally offers ESS as benefit. The management, to a certain extent, is the position of a reeve [23]. By setting land aside in EMS, the management shall create improved natural conditions (for example, natural pest control, pollination, soil fertility, etc.; they are provided as ESS). For us ESS are specifically measured in wished BD (at species level). This way ESS increase; benefits from ESS (to produce more food or reduce costs in food production) can be reaped privately. A prerequisite for reaping benefits from ESS is collective action (ESS built on feasibly for a EMS matrix as nature matrix; this has been already suggested for instance by for BD [24]. For the more general nature matrix issue see Perfecto and Vandermeer [25]. The aspect of a sound ecological matrix [26] (matrix instead of structure) is important for ESS because it relates BD with visibility. Since in many communities the open access situation of no-remaining nature (reduced BD) has created the opposite (low ESS provision), there is no willingness to contribute and mostly no ESS. We think that an active management is needed to promote and optimize EMSs. Soon, we will discuss in detail how a joint and empirically founded exploration of private and natural allocation of land and labour is justified by reasons of collective action [27]. This shall be interest driven. In doing so, we link species appearance BD and management of ESS (by EMS), as well as interest (I); all which are habitat (field margin) oriented.

As a reminder for a normative institutional design, we have to further investigate how access of public management to private labour can improve the system (provision commitment as compromise). Investigating labour shall provide us with a hybrid between markets and governance. In modelling access to labour (also important for ESS), we will show how natural conditions for species appearance can be improved by working for EMS efficacy. To provide additional services accrued through some (farm) labour (though limited), such labour (in reality perhaps only a minor portion) comes under control the public. Especially the access to labour is an issue; all of this helps us to investigate different institutional settings.

To distinguish institutions: (i) beyond land in EMS we have to show how (ii) control over part of local labour (farmers agree) changes livelihoods of farmers being more or less dependent on ESS (visibly improved BD). We might ask, what are the implications of such political economy systems as compared to other mechanisms (no enforcement)? Note that, low or full enforcement of labour under local conditions is a subject to be agreed upon in a community. (iii) A solution might be to offer participation in diverse communities. (iv) We investigate impacts on/of ESS by allowing competition (migration) between communities (choices). This is a moderate enforcement. It might help to restrain command as limited. Competition between communities on labour is expressed as choice. Options to migrate from one community to the other at competitive wage rates can tame the Leviathan as shown. 


\subsection{Property Rights, Biological Aspects of Species Occurence and Land}

In a first outline of the conceptual framework, we already started to make remarks on rights and obligation in EMS. Further discussion is needed. However a full assignment of property rights to natural resources is not a simple task. It may in fact be an impossible one [28]. Therefore, we suggest a modest version of property rights assignment. From an economic oriented point of view it may be sufficient (ii) to assign rights to an ecologist only for economically valuable species. (iii) But does it mean that farmers have to pay for only the service of visible species? (iii) Do we have a market PES where farmers are incentivized to do the job? In contrast, a closer look at desired ecological pre-conditions in farming may reveal (iv) that complex interactions of different species prevail. This implies for management along the priority setting that (v) a certain prevalence of nature (matrix) in a landscape [29] is needed that goes beyond a single farm, as well as (vi) commodification of BD and ESS (again even at farm level) does (not) work. However, we have to look at landscape level. For instance, as a major contribution to an ecologically sound landscape (EMS) for ESS provision (through an environment that selectively supports ESS appreciated as EMS) planning is needed at the interface of land users and nature managers. Then property rights on design are with the manager. Planned EMS and ESS are CPRs, apparently at different scales. Yet, it can be hoped (from a community level analysis) that certain activities (see below for the frame) deliberately work for ESS. For instance, in a watershed, a valley, a wetland, etc., farmland has to be set aside for field margins, hedges, stone walls, and so on. In the provided nature $\mathrm{BD}$ and habitats depend on hot spots but also on stepping stones; in another version corridors can contribute to linking habitats in a net; in fact only this provides a consistent habitat outlay. Ecologists very often depict a healthy ecological system by describing nets and corresponding net outlines over larger area. They see landscape orientation (eco-nets) as measures to improve diversity in landscapes (with specific BD [30]). But ecologists frequently forget to consider liabilities for provision, rights, etc., and rarely outline provision as collective behavioral response, but to be enforced by public management. The process of organizing provision of $\mathrm{BD}$ as regulation needs a deeper insight, for instance, into land provision at the appropriate spatial scale, i.e. community efforts etc. In economic terms, habitat provision is rule-setting like inflowing coercion [31].

In the next step it has to be appreciated that nature production functions should entail synergies between land parcels and should eventually focus on needed (hot) spots to be efficient. The right and obligation to establish synergies are with management. Specific lands must be given priority and we should see focused laboring for specific nominated commons. In a social science oriented analysis (here on spatial connectivity) coercion must be selective; one must clarify the necessary priorities of managers in ESS provision: i.e. to balance needs and find bearable efforts (against universal rules and this may differ from ecolo- 
gists' positions) that are site specific. Finding a compromise might be a tough job. That brings us to the point that management must be analytically built around a negotiation model of detailed compromises. Under such circumstances, job descriptions for the management and the public, as well as bargaining with enabled actors to get ESS as CPR is crucial. Assuming that a constellation of willing farmers exists, they have to be coordinated. Farmers will eventually trade land for labor (or money if extended to monetary valuation) under rules to be set. We see farmers negotiating on rights with management and simultaneously farmers are beneficiaries seeking gains from management at minimal contribution. Then, gains need to be made transparent from ES (ESS become natural capital); but how? Also, for a detailed study we need to extend work on practical aspects (Who uses ESS most?) and guidance to farmers on such practices (Who does what for nature?); but this is beyond our given simplified frame.

\section{Nature Provision and Management}

\subsection{Individual Land and Eco-Net Allocation}

For a deeper understanding of the management problem we use the example of modern farming with large fields and traditional farming. Modern farmers may still know a lot of things about links between ESS and landscape, but they discount such landscape because of high costs imposed by mechanization. The issue is: when we compare old and new landscapes for ESS provision, diversity matters for ecology; but not for the economy. As can be illustrated in Figures 1-3 by diversity insight in landscapes, the conflict is on basis of ESS provision: habitats, nets and remaining nature. Note, the figures only serve as an illustration, not a proof. For a practical delineation one definitely needs a modelling of the most appropriate way of inclusion of spatial frameworks (above) to get species for ESS, and design of nature elements usually follows a complex modelling

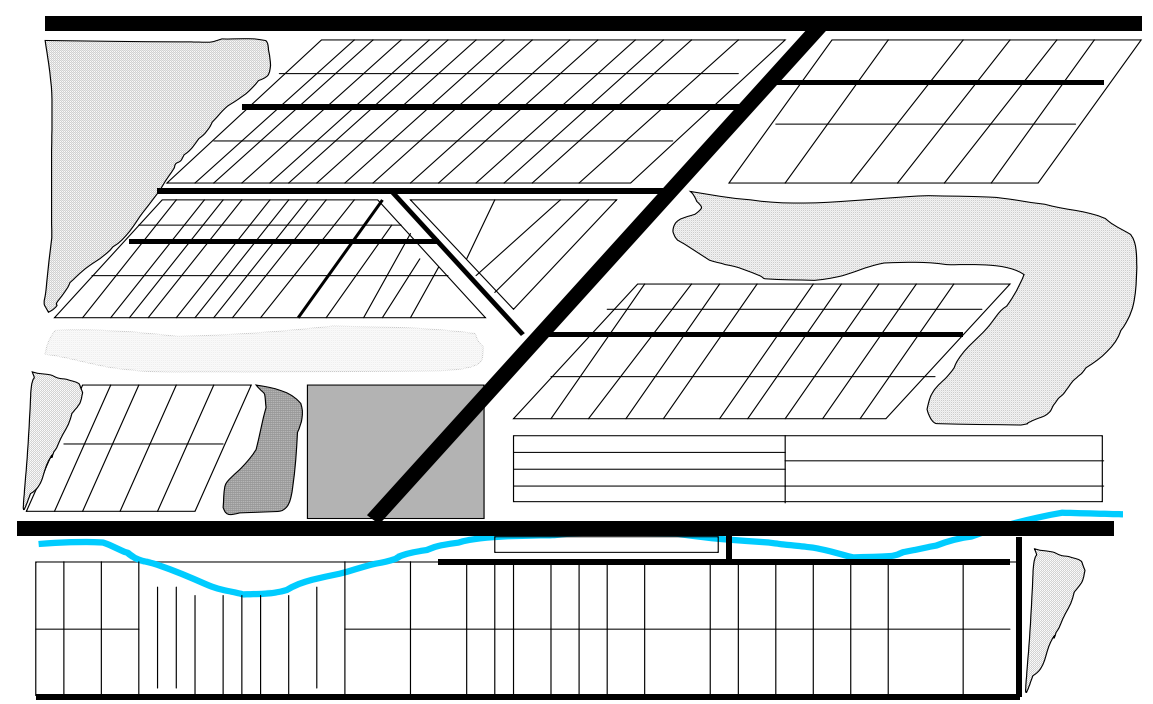

Figure 1. Modern land use structure. 


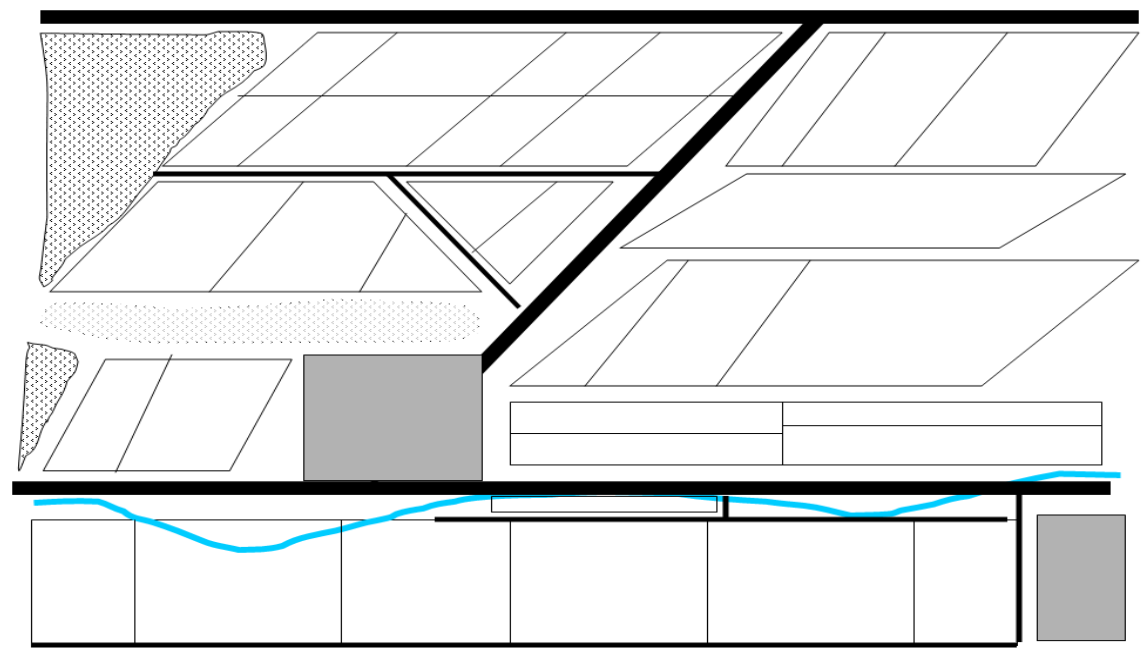

Figure 2. Traditional land use structure.

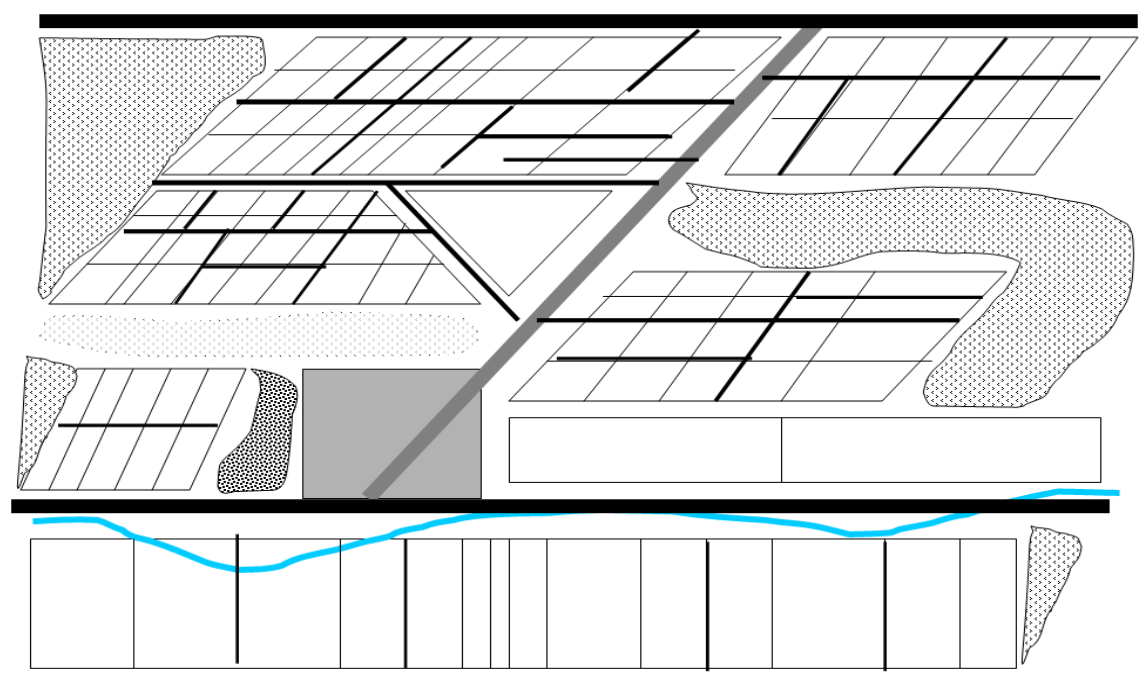

Figure 3. Landscape compromise including an eco-net as main-structure.

which can eventually only be carried out by a combination of ecological and economic models [32]. Additionally we will suggest field margins as highlighted in Figure 3 where bold lines to field edges indicate the potential weaving of a net of habitats. Land use is decided by farmers and the management; management is supposed to offer habitats for ESSs. Particularly field edges, re-combinations of small fields, wetlands, hedges (space), etc.; these are important elements and tools for habitat design and management. They constitute a nature matrix for ESS [33] based on ecological diversity and linking. Additionally, in extended systems, which may include secondary forests, offering organic matter, residues, straw and litter from wilderness, farmers start to appreciate deliveries of ESS at landscape level (including non-timber forest products); i.e. if they are scarce of ESSs. As example, in programming research has tried to add field margins [34] and created a nature matrix. But landscape-ecology-design is still multifaceted in reality. 


\subsection{Formal Depiction and Operationalizing}

To become operational, our argument on nature provision will focus on spatial land use (design for habitats) where individuals in a community contribute to and benefit from an EMS [35]. As said, one can perceive land use as a network of land strips, corridors or field margins; that can be arranged by farmers as strips and adjoining fields (we need to assume a spatially systematic background. Fields and EMS are separable. We assume uncontrolled residual farming in fields and controlled margins by authorities. Farmers contribute to the common [36] and they may identify nature elements as their countryside, i.e. if efforts become linked. Efforts will be bargained [see later [37]). A crucial entity is recognition of dependency at species prevalence and habitat appearance in an eco-net (EMS) and mapping them [38].

For a mathematical simplification of BD provision, we assume that a matrix $\Omega$ exists that converts a vector of habitats " $h$ " in a vector of species "s" (equivalent to a production function (1) but detailed). The matrix can be thought of as a probability oriented depiction that is given as a Markov model. That model tells us, as a two-sided measure, how to "accomplish" species vector $s_{\mathrm{i}}$ living in habitats $h_{j}$.Vice versa, since species need support by multiple habitats $h_{p}$ the linear combination $\Omega_{11}$ guarantees a composition of habitats that supports "s". For the sake of dealing with several communities we also classify $s_{1}$ as species vector in a community.

$$
s_{1} \geq \Omega_{11} h_{1}
$$

where $s_{1}=\left[s_{11}, s_{21}, \cdots, s_{i 1}, \cdots, s_{n 1}\right]$ is a vector of species (trees, birds, etc.), here of interest to farmers as members of community 1 , and $s_{1}$ will change cost functions (see below). A broad range of BD such as flowers, insects, birds, etc. can be included for ESS. The knowledge on needed species shall be derived from landscape ecologists (eventual also managers at site) specialized in ESS (here we assume it exists, perhaps site specific, etc.).

Again, habitats, that are generated, support or coincide with a desired composition of nature, for instance, in terms of green belts, stepping stones, etc.; they can be identified and described by sizes: $h_{1}=\left[h_{11}, h_{21}, \cdots, h_{i 1}, \cdots, h_{n 1}\right]$. It is up to the ecologist as the public manager to discuss, classify and constitute habitats. The prescription relies on biological information, and also human activities are involved (will be shown later; note this is an issue that ecologist may have different views on than farmers). An essential "design" problem emerges with the choice of sizes of habitats as related to set-aside land. As we distinguish the two components: natural (land) and man-made (labour), this gears further habitat quality (2). It brings about a linear combination (mathematically) between size of distinguishable habitats and set aside area.

$$
h_{1}=\left[\Omega_{21}+\Gamma_{11}\right] a_{1} b_{1}
$$

We work with a stretch $a \cdot b$ on land to get sizes. The natural knowledge $\Omega_{21}$, as before, provides a transition matrix of converting a land vector, $b_{1}$ of field stretch 
(EMS broken down into field lengths: $a_{1}$ and with $(1-b)$ ) into a habitat vector $h_{1}$. The vector addresses parcels of land specifically offered by individuals (farmers) in EMS. Specified land parcels can be individually addressed in their potential to create differently important habitats; also synergetic effects exist between habitats and they are expressed explicitly. This is why we need public management and design. In terms of right the manager must have access to land needed for ESS. Then the new element, matrix $\Gamma_{11}$, is an extra matrix that supports habitat creation as labor further promoting provision. The matrix can, in principle, be understood as depicting labor efforts (cultivating activities) that do not ultimately create habitat development, but support habitats additionally in better functioning. For example, propagation of most effective habitats provision for species, here on parcels that are spatially explicit and farm related can be moreover labor requiring. In modeling provision (1) and (2) we assume that any habitat which supports BD in terms of promoting habitats, $j$, on land, $i$, requires a certain extra amount of labor that has opportunity costs or is part of bargaining (see below). The link (3) between labor and habitat creation can be recovered from modelling a linear combination of specific labor as support measures; this labor supports ESS as habitat add-on if it is under management. Consequently labor on a plot $\mathrm{i}$ for habitat $\mathrm{j}$ has to be managed in order to support $\mathrm{h}$ as measure $\Gamma_{11}$ for $s_{1}$. Technically, we speak of a matrix $\Gamma_{11}$ that links nature and labor by a coefficient matrix $\Theta_{1}$. $\Theta_{1}$ expresses the knowledge of a manager on converting labor into habitat and ESS cultivation. For instance, one can think of tree cutting, seed proliferation, ditch creating, etc.; the word cultivation is used here for the things that actors do in order to create a habitat/ESS (matrix) for desired BD. It is qualified as ESS based on BD if it is visible. We suggest provisioning/backing of $\mathrm{BD}$ by humans in terms of public labor; as it reduces cost in food production beyond farms, in that case as per unit costs.

$$
\Gamma_{111}=\Theta L_{1}
$$

Outline (1) to (3) is on a complex relationship between labor, decision making and semi-natural species provision (as a composition). It can be understood as transforming inputs into outputs. To support nature as BD based on human activities, both, land $b_{1}$ and labor $L_{1}$ management, is needed at habitat level. Bringing elements together we receive presentation (4): a species vector dependent on allocation: $b_{1}$ and labor $L_{1}$. That shall be sufficient to obtain semi-natural practices of creation of wished BD in a landscape and enable spatial priorities.

$$
s_{1}=\Omega_{11}\left[\Omega_{21}+\Theta L_{1}\right] a_{1} b_{1}
$$

where: $a_{1}=$ vector of field sizes

$b_{1}=$ percentage for habitats

$L_{1}=$ labor for habitat and species

Now, the task for manager of the public good BD ( $s_{1}$ : ESS in community 1 as used in the later outline) is to find out how much of $b_{1}$ and $L_{1}$ should be invested, given individual and public interests (costs) in a community. ESS and opportu- 
nity costs for land and labor are balanced as willingness to contribute and benefit by farmers as well as we seek management objectives.

\section{Objective Functions Due to Land Allocation for Species Occurrence}

In this section the focus is on a description of "how to model adjusting farms and provision of land for habitats" (for BD/ESS) by objectives. We deal with two aspects: (i) A possible provision of field margins by farmers based on own objectives, etc.; i.e. show how could it be established? (ii) It has to be understood why profit maximizing farmers usually have limited incentives to provide ESS (tragedy of commons). To do so we use approaches on farm economics in land use/landscapes. We refer to Röhm and Dabbert [39] who linked spatial modelling to profit functions, but we may stylize the farm operations and landscape appearance.

In our model, profits from land use are to be distinguished between conventional farming on remaining fields and conditional use (returns) on field margins: i.e. buffers in case of no harvests [40] or given restrictions in farm practices. Though we stick to an outline of actual farm size/field structures, land occupation might be flexible. For example, it depends on biological interests and classification of margins (such as grassland). Whether margins can be mowed and provide forage is not elaborated. At EMS level positive effects (cost reduction due to biological activity/ESS) are expected if instructions of ecological management prevail and this is portrayed as eco-farming in contrast to intensive farming. In general, landscape elements such as hedges and any long term structures can be applied. What is important: (i) ESS are depend on size of EMS, (ii) that a positive net effect is postulated for farm profits from ESS and (iii) EES shall substitute chemical practices, such as spraying, etc. For us the public-good aspect of nature matters in EMS (eco-net). For instance, assuming only one farm is doing field margin provision; in such case, a landscape sees low positive effects (few ESS). Effects are marginal. Positive effects on ESS can only be realized by many farms (as efforts in landscapes). It is vital that landowners in the area get noticed of positive external effects as joint product, but it is difficult to make only an individual cost-benefit-analysis. ESSs are themselves living and agronomy topics.

Next, the agricultural economy arguments for nature provision (within a community of many farmers) can run as follows: (i) harvests (also from margins) remain private. (ii) Adjusted total profit is recalculated using crop yields depending on ESS, first, at remaining conventional field and, second on margins. (iii) Thus, profits are mainly determined by land allocation between rest of field (usual farming) and margins (size matters). (iv) Then the objective function (5) of a representative farmer in margin provision corresponds to a constrained optimization approach. Such constrained optimization and corresponding dual approaches are frequently used in production economics; but now we adjust it to 
the case of land allocation; it includes indirectly a supply of a public good. Notice that " $\mathrm{s}$ " is a vector of ESS.

$$
I_{i}^{u}=\sum_{j}\left[p_{j}^{u} a_{j}\left(1-b_{j}\right)+c_{j}^{r} a_{j} b_{i j}-C\left(\left(1-b_{i j}\right), s_{i}, l_{j}, L_{i}, r_{j}\right)\right]
$$

where:

$$
\begin{aligned}
& I_{j}^{u}=\text { as profit } \\
& c_{j}^{r}=\text { compensation of restricted ecology favoring agriculture, (profit } \Uparrow \text { ) } \\
& \left.b_{j}=\text { size change of the field i on farm } \mathrm{j}, \text { area cropped, (profit } \downarrow\right) \\
& L_{j}=\text { Labor } \mathrm{j} \text { on farm j, for nature (profit } \downarrow \text { ) } \\
& C(.)=\text { cost at quantity of } q_{i j} \text { of field } l_{i j} \text { with the yield } h=q_{i j} / I_{i j} \text { (cost } \Uparrow=>\text { prof- }
\end{aligned}
$$
it $\downarrow$ )

$b_{i j}=$ field margins, cost reducing biological activity (cost $\downarrow=>$ profit $\Uparrow$ )

$s=$ species vector, ecological effect from a eco-net

$I_{j}=$ labor for nature, labor for habitat improving $(\operatorname{cost} \uparrow=>$ profit $\downarrow)$

$r_{j}=$ input costs, farm specific (cost $\Uparrow=>$ profit $\left.\downarrow\right)$

The alike (5') offers an expression of inclusion of contribution of all farmers; inserting for $\mathrm{s}$

$I_{i}^{u}=\sum_{j}\left[p_{j}^{u} a_{j}\left(1-b_{j}\right)+c_{j}^{r} a_{j} b_{i j}-C\left(\left(1-b_{i j}\right), b_{j}, \Omega_{11}\left[\Omega_{21}+\Theta L_{1}\right] a_{j} b_{i j}^{*}, l_{j}, L_{i j}^{*}, r_{j}\right)\right]$

It expresses the provision of ESS as farm decision model and landscape design problem. By (5') we can use a model farm behavior as dependent on individual and collective contributions, i.e. a vector $b_{i}$, to get an EMS. Specifically, in the eye of a farmer, only contributions of cooperative partner $b_{i j}$ result in "s" (as public good of desired BD; note: for dis-services the model must be more complex). Yet, a community of farmers may decide sizes $b_{i j}^{*}$ for an EMS (below public management) and this offers "s" ("b" is the source of habitats composed of individual $b_{i p}$ i.e. percentages delivered to EMS by member $\mathrm{j}$ by farm and field). Ideally, this should happen because of the farmers' will (as an expression of a community interest and then by some coercion) requires them to deliver allocations of margins. The question is what type of behaviour is this and how we can model this behaviour in a landscape? For the sake of simplification and illustration, firstly, let us consider a benevolent dictator hypothesis. For that we take a sector line with diverse farmers. It implies that a profit sum in activities is:

$$
\Pi_{c}^{u}=\sum_{i} \sum_{j}\left[p_{j}^{u} a_{j}\left(1-b_{j}\right)+p_{j}^{r} a_{j} b_{i j}-C\left(\left(1-b_{i j}\right), b_{j}, s, l_{j}, L_{j}, r_{j}\right)\right]
$$

Now a community function (6) prevails. It is explicitly re-specified. For the cost function we use a quadratic function (7). A quadratic cost function provides linear derivatives and (7) rechecks cross effects as well it can be empirically evaluated.

$$
\begin{aligned}
C\left(\left(1-b_{j}\right), b_{j}, s, r\right)= & \gamma_{01 j} b_{j}+\gamma_{02 j}^{\prime} s+0.5 b_{j}^{\prime} \gamma_{1 j} b_{j}+\gamma_{2 j} b_{j} r_{j} \\
& +0.5 s^{\prime} \Gamma_{1 j} s+0.5 s^{\prime} \Gamma_{1 j} L_{1 j} 1+\gamma_{2 j}^{\prime} s r_{j}
\end{aligned}
$$

About coefficients and constraints in (7): in order to find coefficients in front 
of $\mathrm{s}, \mathrm{b}$ and $\mathrm{L}$, one can use maximum entropy can be used to get coefficients for effects in constrained behavior. Equation (7) can be best evaluated in programming farms that show different practices (given mixed or specialized farming in landscapes; i.e. (7) will look different for farms and ESS count differently). Summing up the number of participants in a landscape and expressing the summation in a matrix version one gets merging coefficients as representation of a community. (We dropped "a" for area, now in $\mathrm{p}_{\mathrm{i}}$ ).

$$
\begin{aligned}
I_{i}^{u}= & p_{i}^{u}\left(1-b_{1}\right)+p_{1}^{r} b_{1}-\gamma_{011} b_{1}-\gamma_{021} s_{1}+0.5 \cdot b_{1}^{\prime} \Gamma_{111} b_{1}-0.5 \cdot s_{1}^{\prime} \Gamma_{211} s_{1} \\
& +1_{1}^{\prime} L_{1} \Gamma_{32} s_{1}+b_{1}^{\prime} \Gamma_{311} s_{1}-b_{1}^{\prime} \Gamma_{411} r_{1}-b_{1}^{\prime} \Gamma_{511} r_{1}
\end{aligned}
$$

In version (8) variables are vectors given by (i) a vector "b" (field margins: negative) and (ii) "s" (positive, again for reference to geometry in landscape; for GIS a version of habitats; and " $\mathrm{s}$ " are appreciated BD for landscape-wide ESS. Wished BD is a vector for selected ESS "s" (cost reducing); (iii) "p" gross margins and (iv) "L" labor; it is also organized by groups (in matrix way). Variables "b" and "L" reflect private and public contributions; they look likewise as management and design problems for " $s$ " and promote profits (benefits concerned), dependent on the capability to get "b" and "L" optimized.

Equation (8) is a community (group) wide profit function (sum of single profits) that includes nature as $\mathrm{BD}$ (public species). ESS gained from nature (species) means that BD impacts on cost functions (reduced) of farmers via ESS. Since nature requires habitats and spatial setups that cross farm borders, "s" only impacts synergistically if farmers pool " $\mathrm{s"} \mathrm{(public} \mathrm{good),} \mathrm{"} \mathrm{s}$ " is positive; but " $\mathrm{s}$ " is differently aiding farmers. However, nature is a relevant input " $s$ " and it needs design. Finally, nature " $\mathrm{s}$ " is not neutral, but rather positive. (This can be disputed in a more complex case of negative effects from nature: see wolves). Vector "s" (in costs) actually is the positive impact and is flexible; but perhaps preys and predators count in the community. For instance, eagles killing sheep can be included, if it stabilises eco-systems and service.

\section{Manager, Objective Functions and Leviathan}

\subsection{Social Welfare}

Now the question emerges: What is the role of public management (of a reeve) in design? We will pursue the idea of a reeve (Leviathan as a public manager) of $\mathrm{CPR}$ and show how in a model the task of nature provision "b" can be pursued applying economic principles for optimal behaviour. The manager shall have power to impose statutory regulations on (so called) waivers in land use (b, as delivery to nets which is job assignment) and regulations are derived from optimization. As we need a reference we start with a socially optimal behaviour. It means that the manager is neutral and has no self-interest. (Later we use optimization as bargaining tool.) Species occurrence " $\mathrm{s}$ " is an intermediary objective (target by which efficiency of management is judged). One can think: a manager (regulating reeve) enhances welfare of farmers (on behalf of them) which lets 
him/her spare habitat land and procure labour. Since we work with a model as vectors, management optimizes ESS provision technically at community level. In a first step " $\mathrm{s}$ " is a determining variable for the costs in (9):

$$
\begin{aligned}
I_{1}^{c}= & p_{i}^{\prime}\left(1-\boldsymbol{b}_{1}\right)+p_{1}^{r^{\prime}} \boldsymbol{b}_{1}-\gamma_{011}^{\prime} \boldsymbol{b}_{1}-\gamma_{021}^{\prime} \boldsymbol{s}_{1}-\gamma_{031}^{\prime} \boldsymbol{l}_{1}+0.5 \cdot \boldsymbol{b}_{1}^{\prime} \Gamma_{11} \boldsymbol{b}_{1}+0.5 \cdot \boldsymbol{s}_{1}^{\prime} \Gamma_{21} \boldsymbol{s}_{1} \\
& -\boldsymbol{b}_{1}^{\prime} \Gamma_{41} \boldsymbol{s}_{1}-\boldsymbol{b}_{1}^{\prime} \Gamma_{51} \boldsymbol{l}_{1}-\boldsymbol{l}_{1} \Gamma_{61} \boldsymbol{s}_{1}-r_{1}^{\prime} \Gamma_{71} \boldsymbol{b}_{1}-r_{1}^{\prime} \Gamma_{81} \boldsymbol{s}_{1}-r_{1}^{\prime} \Gamma_{91} \boldsymbol{l}_{1}
\end{aligned}
$$

By inserting "s" we make optimization in Equation (4) endogenous and express social benefit of a community 1 solely as a function of $b_{1}$ and $L_{11}$. This ends in collective welfare such as (10). In Equation (10) farmers are individually owning land and labour is constrained, and allocation decisions towards the common (pool) as habitats determine the social optimum.

$$
\begin{aligned}
I_{1}^{c}= & p_{1}^{\prime}\left(1-\mathbf{b}_{1}\right)+p_{1}^{r^{\prime}} \mathbf{b}_{1}-\left[\gamma_{011}^{\prime}+\gamma_{021}^{\prime} \Omega_{11}\left[\Omega_{21}+\Theta_{1} \mathbf{L}_{11}+r_{1} \Gamma_{81}\right]-r_{1}^{\prime} \Gamma_{71}\right] \mathbf{b}_{1} \\
& -\gamma_{031}^{\prime}\left[\mathbf{l}_{1}^{*}-\mathbf{L}_{11} 1\right]+0.5 \cdot \mathbf{b}_{1}^{\prime} \Gamma_{11} \mathbf{b}_{1}+0.5 \cdot\left[\mathbf{l}_{1}^{*}-\mathbf{L}_{11} 1\right]^{\prime} \Gamma_{31}\left[\mathbf{l}_{1}^{*}-\mathbf{L}_{11} 1\right] \\
& -\mathbf{b}_{1}^{\prime} \Gamma_{51}\left[\mathbf{l}_{1}^{*}-\mathbf{L}_{11} 1\right]-r_{1}^{\prime} \Gamma_{91}\left[\mathbf{l}_{1}^{*}-\mathbf{L}_{11}\right]
\end{aligned}
$$

Technically, in (11a and b) we optimize social welfare by derivatives, here adhering to ESS provision which is dependent on public management $b$ and $\mathrm{L}$. It can be expanded to an optimization along a benefits-cost analysis by separating first derivatives of $\mathrm{b}$ and $\mathrm{L}$ between users and providers. Optimization for the community as a whole, yet knowing farmers, gives:

$$
\begin{aligned}
\partial I_{i}^{u} / \partial_{1} \mathbf{b}_{1}= & -p_{1}^{\prime}+p_{1}^{r^{\prime}}-\left[\gamma_{011}^{\prime}+\gamma_{021}^{\prime} \Omega_{11}\left[\Omega_{21}+\Theta_{1} \mathbf{L}_{11}+r_{1}^{\prime} \Gamma_{81}\right]-r_{1}^{\prime} \Gamma_{71}\right] \\
& +\Gamma_{11} \mathbf{b}_{1}-\Gamma_{51}^{\prime}\left[\mathbf{l}_{1}^{*}-\mathbf{L}_{11} 1\right]=0 \\
\partial I_{i}^{u} / \partial_{1} \mathbf{L}_{11}= & \gamma_{021}^{\prime} \Omega_{11} \Theta_{1} \mathbf{b}_{1}+\gamma_{031}^{\prime}+\Gamma_{31}\left[\mathbf{l}_{1}^{*}-\mathbf{L}_{11} 1\right] \mathbf{l}_{1}^{* \prime}-\Gamma_{51} \mathbf{b}_{1}^{\prime}-\Gamma_{91} r_{1}^{\prime}=0
\end{aligned}
$$

Optimization (11) is vector and matrix optimization, which engages a technic of Theil [41] a given problem of finding best $b$ elements in fields and allocating labour $\mathrm{L}$ to them.

\subsection{Rearranging for Labor and Land Access}

Yet, an issue might evolve where the manager pursues his own agenda on species conservation (for example, being an ecologist who wants to maximize a specific species appearance; for example many wolves). This would imply a much higher use of conservation land and labour than compared to the interest of farmers (bees); at least from an economic point of view where welfare is defined as willingness to pay or accept, there is conflict. How to cope with interest of the manager? The above presentation of an optimized social welfare is only a reference not containing interest of ecologists. Institutions depend on different ESS perception (i.e. land set aside vs. habitats). To solve it, we can refer to tasks of managers: (i) land allocation for habitats has to be reorganized finding appropriate levels suiting farmers and preservation and (ii) organizing labour. But still there might be an interest for a special BD. In traditional language: a reeve may organize farmer because of (feudal) rents. Simply what happens if the 
manager has his own agenda? There might be an agreement that only certain amounts of land and labour can be devoted to public interest. Then taming reeves is in on the agenda. For taming it may be sufficient that total access is capped.

Still, it shall be a self-ruled community; the manager has access to land and labour, but limited (capped by a consensus). Then it is a regulated optimization and eventually voting gives the cap in total. The critical aspect is how to find a way of modelling for optimization under rules of constrained access imposing a cap; but it can be stated that this is suboptimal. The idea is to assure that public management does not override community-wide agreed private rights, so the deal would be to limit access; this might be stated as a community rule. In a simple version (for above specification) we can just add limits (12). The question is, what is an alternative (to farmers who fear to be overridden)? However, limiting rights can work (still as for a benevolent dictator). First of all, as a reference, we might optimize Equation (12) to find a second best solution to nature provision in a community, here with reference to a rule of upper-limit labour and land use being agreed. Social welfare optimization can use the formula.

$$
\begin{aligned}
I_{1}^{c}= & p_{1}^{\prime}\left(1-\mathbf{b}_{1}\right)+p_{1}^{r^{\prime}} \mathbf{b}_{1}-\left[\gamma_{011}^{\prime}+\gamma_{021}^{\prime} \Omega_{11}\left[\Omega_{21}+\Theta_{1} \mathbf{L}_{11}+r_{1}^{\prime} \Gamma_{81}\right]-r_{1}^{\prime} \Gamma_{71}\right] \mathbf{b}_{1} \\
& -\gamma_{031}^{\prime}\left[\mathbf{l}_{1}^{*}-\mathbf{L}_{11} 1\right]+0.5 \cdot \mathbf{b}_{1}^{\prime} \Gamma_{11} \mathbf{b}_{1}+0.5 \cdot\left[\mathbf{l}_{1}^{*}-\mathbf{L}_{11} 1\right]^{\prime} \Gamma_{31}\left[\mathbf{l}_{1}^{*}-\mathbf{L}_{11} 1\right] \\
& -\mathbf{b}_{1}^{\prime} \Gamma_{51} \mathbf{L}_{11}\left[\mathbf{l}_{1}^{*}-\mathbf{L}_{11} 1\right]-r_{1}^{\prime} \Gamma_{91}\left[\mathbf{l}_{1}^{*}-\mathbf{L}_{11} 1\right] b^{*} \\
& +\lambda_{1}\left[l-1^{\prime}\left[\mathbf{l}_{1,0}^{*}-\mathbf{L}_{11} 1\right]\right]+\lambda_{2}\left[h_{1,0}-\mathbf{1}^{\prime} \mathbf{b}_{1}\right] b^{*}
\end{aligned}
$$

Formula (12) presents behaviour of a manager (reeve) who has a cap on land acquisition; the group has artificially introduced a physical constraint on rights on land and labour for statutory regulation. The result is a set of shadow prices on land and labour. These shadow prices can be equated with land rents and wage rates of farmers and a quasi-exchange system could be established. Then individual costs and benefits are calculated from achieved " $\mathrm{s}$ ". In version 1: land is fixed; in version 2: a priced supply of land and labour prevails. Constraints can be monetary if we know prices of land and labour. Anyway, (12) is flexible to get a meta-equating of land and labour prices. Then the reeve gets a rent. Not yet full, but we can include a bonus for him on shadow prices. In advanced versions we might take some incomes of benefiting farms (with eco-nets contribution) and give it to the public manager incentivizing him.

\section{Political Economy Bargaining Model and Game Solution}

For the rest of the article we take another routing and engage in political economy. Political economy modelling can serve to come closer to a scheme in which design and coercion of managers play a role. In yet a conceptual note, differences between a benevolent and a partial manager must be intensively discussed. The crucial aspect is the creation of the manager's own interest. A partial man- 
ager shall allocate land set aside better than an impartial manager because his own interest is involved. How to do it? As shown, in different regimes applied to eco-nets, power of managers plays an important role (zero power is with no interest; but interest has to be created. In reality, a community does not have the choice between "tragedy of the common" and an "impartial reeve". It can give managers political power to enforce statutory regulations, but also sets limits. A benevolent manager is unrealistic, but a partial manager is subject to influence. So what can be done? A situation with a partial manager coincides with political bargaining. Such bargaining model can adopt Harsanyi's multiple-agent work [42] and it is the task of modelling to specify interest functions of the manager and farms in (13):

$$
L=\left[\prod_{j}\left(I_{j}-I_{j}^{0}\right)\right]\left(I_{m}-I_{m}^{0}\right)
$$

where: $I_{j}$ : interest of farmer in $b$ and $L$

$I_{m}$ : interest of manager in $b$ and $L$.

Note that we are not dealing with a debate on a democratic vs. a hierarchical solution nor will we talk about causes for successful CPR management as well as evolution of regimes. Rather, we opt for a mathematical presentation of a bargaining solution (13), we refer to a situation with lobbying and interest. For explanation: in (13) $I^{0}$ is a reference of no public action and $I_{j}$ is calculated on the basis of mutual achievements in bargaining. We assert that the manager's interest is in special species, i.e. if he comes from ecology. (S) he receives rights, and land and labour are controlled. Technically (13) maximizes the product of differences between cooperation ( $I_{j}$ by participants and $I_{m}$ manager) in a game and possible disagreement is $I_{j}^{0}$ (Rausser and Zusman, see below under [43]). The manager $\mathrm{m}$ is subject to lobbying for " $\mathrm{s}$ " which increases his welfare (interest: individuals seek rents). (It is not the task of the paper to go in detail of the bargaining process itself). We will use (13) and show how it can be expressed. Taking the logarithm of specification, a political bargaining function as the sum of lobbying activities $g_{j}=g\left(c_{j}, \alpha_{j}\right)$ function (14) is a goal to be optimized:

$$
\ln W=\ln \left[I_{c}-I_{m}^{0}+\sum_{j} g\left(c_{j}, \alpha\right)\right]-\ln \left[\sum_{j} w_{j}\left[I_{j}-I_{j}^{0}-c_{j}^{0}\right]\right]
$$

where: $I_{\dot{c}}$ is the welfare of the community

$I_{j}$ is the individual welfare of farmers.

$g_{j}$ "political gifts" by $\mathrm{j}$ to the manager

$c_{j}$ : "costs of lobbying" of $\mathrm{j}$

Equation (14) gives, as a residual after approximation, a weighted objective function (15) of a community, in which weights are derived from power (a calculation from function (16)). The primary objective function (goal) is a reduced form in which we have to find the references.

$$
W^{*}=I_{m}+\sum_{j} w_{j}\left[I_{j}-I_{j}^{0}-c_{j}^{0}\right]+\sum_{j} g\left(c_{j}^{0}, \alpha\right)-I_{m}^{0}
$$


Yet, weights can be rescued from a parallel analysis on references (i.e. not to join) in a hierarchal game. Then one can work with referenced interests as done by Rausser and Harsanyi.

$$
w_{j}=\left(I_{j}-I_{j}^{0}\right) /\left(I_{m}-I_{m}^{0}\right)
$$

The weights can either be summarized to one or the weight of the manager is given as $\left[1-\Sigma \mathrm{w}_{\mathrm{i}}\right]$. Power is indicated by weight. It is acquired from the threat not to cooperate minus reference interest. (The strategy not to cooperate exists but is not chosen.) The crucial point is to derive weights technically by taking derivatives (17) and using them in a normative analysis. Finding weights is an interactive task, which can be solved in participatory approaches.

$$
w_{1} ; \cdots ; w_{j}=\frac{I_{C}^{\text {opt. }}-I_{C}^{0}}{I_{j}^{\text {opt. }}-I_{j}^{0}}=\frac{\partial s\left(c_{j}, \delta_{j}\right)}{\partial c_{j}} ; \cdots ; w_{n}
$$

For further interpretation: interest functions are to be calculated on basis of information derived from manager optimization. From this we get weights. Weights recursively determine solutions. Yet we need lobbying functions in cases of modelling. How can the concept be modified and applied is a more appropriate question. A practical option for interest functions detection is to look at farmer and manager for joint regulations and priorities in ESS provision.

\subsection{Interest, Conflicts and Objectives Built on Regulations of Managers}

Above, the objective function of farmers was specified as giving up land and labor for getting ESS. This function can serve as farmers' interest. But for negotiations we also need a manager's interest which shall come from conservation. Usually, political economy modelling works with a monetary interest, i.e. in terms of within payments managers can obtain. For ESS management we need a different objective in which $\mathrm{BD}$ shall dominate as "good" nature. $\mathrm{BD}$ has to be based on specific species getting "interest". Specially, we need an interest for modelling the conflict for different BD among farmers and managers. Because conflict matters, we cannot consider a sterile type of ecological management (on technical aspects). Rather it can be opposite: involvement and authority based on will is needed. For interests of managers several versions can be exemplified. Versions can stretch from a pure ecologist's point of view (maximizing, for instance, bio-diversity) to a landlord's advancing (maximizing land rent if titles are given and farmers are peasants). Also, for farmers we need to adapt versions.

We could see ecologically oriented maximization of $\mathrm{BD}$ as an aim of public management. Famers may disobey. It would be management as if (s)he (manager) has a "right" that farmer deliver " $b$ " and "L" for "s". On the other hand, rights are not fully given; there needs to be a bargain. In the logic of "who wants what $\mathrm{BD}$ s" is perhaps a fitting perception of the current aim in conservation ecology, but on what? A question is how close do we come to interest? The aims of ecological management and farmers differ; regards to land management, ha- 
bitat, etc. How can we get interests formally? We suggest that a $\mathrm{BD}$ is to be given at minimal cost.

To get a start, as in primal programming, activities can be directed to achieve the ecologically oriented BD. To sketch it we apply cost minimization. Then primal optimization gives "optimal" habitat delivery at stated costs. It includes field margins and land as decision variables that are "correctly" controlled by management. The delivery can be inserted in a new goal function, and from a statistical view based on limited information (Maximum Entropy [41]; behavioral equations can be retrieved (see below) for eco-nets. Yet, then interest is an ecological goal (gaged) minus cost to achieve it by b and $\mathrm{L}$.

Concerning the manager's objective, the dual, valued " $b$ ", can be renamed into a constrained "utility" function in which costs per unit of habitat are arguments and BD is a goal. Initially the constraint serves for construction of the objective, but now it is flexible. In effect, because costs for provision are given as reference (benchmark), two types of optimization (primal and dual) are used. Such retrieved objective of an ecological manager is quasi monetary, although it contains ecological goals and behavior as core. The underlying argument is that ecological management is cost constrained, which gives the money aspect of an expenditure equivalent.

\subsection{Manager's Interest}

To work out such interest in detail, i.e. for a mathematical concept of achieving an ecological objective " $\mathrm{s}$ " as goal to be programmed, we suggest dealing with economics of minimizing costs given an ecological target (e.g. a vector of species represents $\mathrm{BD}$ which is envisaged by an ecologist and extern because it is ideally to be achieved). The goal is vector "s" that is broadly obtained by a "technology $A$ ". Technology $A$ is given as knowledge of ecologists seeking land for eco-nets as "a. $(1-b)$ ". An issue is how values " $\lambda_{e}$ " of targets " $s$ " are measured. " $\lambda_{e}$ " is a price type (same as revenue) of benefit of given " $s$ ". At present, " $b$ " is presumably a control variable and is subject to running at unit cost " $c$ ". " $c$ " is farmer's reward.

$$
\operatorname{Min}\left\{c_{1}^{\prime} a_{1} b_{1}\right\} \quad \text { subject to } s \geq A[1-b]
$$

where

$$
\begin{aligned}
& b:=\text { percentage of land provision as activities } \\
& c:=\text { unit costs which exceed the usual cost because farms provide service } \\
& a:=\text { area, i.e. field size }
\end{aligned}
$$

The technical aim is to attain a quadratic objective function for costs from this formulation. It gives managers ecological interest $I_{m}$. We see a linear response for (18) and programming (19); i.e. vector " $\mathrm{s}$ " (prescribed by ecologists) is "essential" for a sane ESS and accomplished in habitats as linear constraint. We use the above code to take the position: optimization from a singular observation of supply is "s"; it is part of a maximum-entropy analysis. In that case, "s" is linked by a linear system (19, incl. L) to control variable " $b$ "; 


$$
\begin{gathered}
s_{1}=\Omega_{11}\left[\Omega_{21}+\Theta L_{1}\right] a_{1} b_{1} \\
\Leftrightarrow s_{1}=\Omega_{11}\left[\Omega_{21}+\Theta L_{1}^{o}\right] a_{1} b_{1}+\Omega_{11}\left[\Omega_{21}+\Theta L_{1}\right] a_{1} b_{1}^{0}
\end{gathered}
$$

where variables are vectors:

$$
s .=\text { target, } \text { i.e. } \text { species vectors }
$$

$\Omega:$ : technology; knowledge of relationships between $\mathrm{s}$ and effort (later landscape design)

$$
b:=\text { effort }
$$

and for later calibration from empirical deliberations we should use a given observation:

$$
s_{1} \geq \widehat{s}_{1}
$$

Further, a dual of the programming (Equations (18) and (19)) provides a function of shadow prices (20). Initiating such notation of dual, (20) maximizes the sum of shadow prices for constraints (here the vector "s", that has to be accomplished and the calibration constraint, is "revenue").

$$
\operatorname{Max}\left\{r_{1}^{\prime} \widehat{s}_{1}+\lambda_{e 1} s_{1}\right\}
$$

where vectors are:

$\lambda_{e}:=$ shadow price

$b:=$ activities of the primal solution

$r=$ values (prices) for empirically observed species vector, eventually given

$s:=$ observed or ideally specified species vectors

Then Equation (21) is a corresponding constraint in a dual optimization. It means a dual solution for shadow price is found with flexible c: shadow price " $\lambda$ " and " $r$ " are matching.

$$
c_{1} \leq \Omega_{11}^{* \prime} \lambda_{e 1}+r^{0}
$$

where labor is fixed, as are the residual determinants in $\mathrm{r}$.

As said, under specific conditions [44], primal and dual, correspond to a devising of cost equivalent values of $\lambda_{e}$ (shadow price) that incur values of constraint expressed in (unit) cost for a list of species [45]. I.e. there is actually a valuation of target (21) at given cost terms to get it. Numerical results can be employed through Maximum Entropy [46]. The method provides a quadratic interest function that stands for programmed results based on observation. For management its interest $I_{m}$ (to get a type of species structure) is tantamount to money spent and it is set as follows:

$$
\begin{aligned}
I_{m}^{\prime} & =c_{1 j}^{\prime} b_{1}-\Phi(\ldots) \\
& =c_{1 j}^{\prime} b_{1}+\lambda_{1 e}\left[s_{1}-\Omega_{11}\left[\Omega_{21}+\Theta L_{1}^{0}\right] a_{1} b_{1}+\Omega_{11}\left[\Omega_{21}+\Theta L_{1}\right] a_{1} b_{1}^{0}\right]
\end{aligned}
$$

where the coefficients are the same as above and variables are:

$b:=$ effort, later specified as landscape design and

$\lambda_{s}:=$ shadow price for species

Objective (22) can be more generic and by ME we get a quadratic foundation 
of coefficients:

$$
\begin{aligned}
I_{m}^{\prime}= & c_{1 j}^{\prime} b_{1}+0.5 b_{j}^{\prime} \Xi_{11 j} b_{1}+\lambda_{e 1} \Xi_{12} b_{1}+0.5 \lambda_{e 1}^{\prime} \Xi_{13} \lambda_{e 1} \\
& +\lambda_{e 1} \Xi_{14}\left[\Omega_{11}\left[\Omega_{21}+\Theta L_{1}\right] a_{1} b_{1}^{0}\right]
\end{aligned}
$$

The function (23) shall express the interest of an ecologically oriented manager. The manager uses money to obtain the habitats/eco-net. So he has to acquire cash as in a political economy framework. Cash can be gained from farmers who benefit from ESS via " $\mathrm{s}$ " and will be a "carrot", the manager shares as benefit. Expression (23) is an artificial interest function. But it can be retrieved from information on the design and cost function farmers have for ESS, using programming. ME analysis [46] is an appropriate method of calibrating models along probable sets of coefficients and it entwines ecological concerns in seemingly unknown interests of a physically oriented ecological management. The Equation (23) has similarity to willingness to pay (WTP) of users for revealing preference " $\mathrm{s}$ ". To see the argument: optimization by programming, i.e. incl. optimal species and calibration of behaviour, is optimal and we can obtain first derivatives giving us behaviour:

$$
\begin{gathered}
\partial I_{m} / \partial b=c_{1 j}^{\prime}-\Xi_{11 j} b_{j}+\Xi_{12} \lambda_{e 11}+\Xi_{14}\left[-\Omega_{11}\left[\Omega_{21}+\Theta L_{1}^{o}\right] a_{1} \lambda_{e 11}\right]=0 \\
\partial I_{m} / \partial \lambda_{e 1}=\Xi_{12} b_{1}+\Omega_{11}\left[\Omega_{21}+\Theta L_{1}\right] a_{1} b_{1}^{0}=s
\end{gathered}
$$

(24a and 24b) tells us how a manager "behaves" towards preferred choices of “ $s$ " (by margins b assignment and labour L). It results in habitats and matching valuation. Derivatives (24a and $24 \mathrm{~b}$ ) cause values $\lambda_{\mathrm{e}}$, which are dependent on land use and shadow price (value) of species. Eliminating " $b$ ", a relationship between $c$ and s prevails, though it still depends on " $L$ ":

$$
c_{1}=\Xi_{11}^{*}-\left[\Xi_{12} \Omega_{13} \Omega_{21}\right] L_{1} 1+s
$$

Then labor can be included (recruited for ESS supply) at stated ecological management costs.

$$
L_{1} 1=\Xi_{11}-\left[\Xi_{12} \Omega_{13} \Omega_{21}\right]^{-1} C_{1}
$$

As extra follow-up: if the consecutive condition (27) holds, it gives a shadow price due to c:

$$
\lambda_{1 e}=\Xi_{11}^{*}\left[\Xi_{11}-\left[\Xi_{12} \Omega_{13} \Omega_{21}\right]\right]^{-1} c_{1}
$$

I.e. if " $\mathrm{c}$ " (compensation) payments for area [1-b] are clarified, they correspond to the valuation, vice versa. Then, as in any individual expenditure-revenue-balancing of a manager, expenditures must equal revenue. The management issue is to offer compensation " $c$ " to providers at regulation " $b$ " for " $s$ " (the adequate compensation is negotiated). The manager, in his own interest, should as well charge the "best" fee for "s" (see below) serving as finance. Condition (27) can be reversed and having $\lambda_{\mathrm{e}}$ it asserts BD as "necessity"; though behaviour can adjust to a new bundle of " $\mathrm{s}$ " as compromise. This implies that management is 
ready to compromise. Overall the interest function of the manager (reeve) allows him to plan "c" and " $\mathrm{f}$ " for getting " $\lambda_{\mathrm{e}}$ ". He as a rent and "s" and " $\lambda_{\mathrm{e}}$ " are balanced and are figured out between ecological knowledge and public demand by farmers, for which we need benefits per unit of " $s$ ". Costs "c" are to be found and are flexible in equilibriums, see:

$$
\begin{aligned}
I_{m}= & \lambda_{e 1} s_{1}-c_{1 j}^{\prime} b_{1}-\Phi_{1}(\ldots) \\
= & \lambda_{e 1} s_{1}-c_{1 j}^{\prime} b_{1}-\lambda_{1 e} \Omega_{11}\left[\Omega_{21}+\Theta L_{1}^{o}\right] a_{1} b_{1} \\
& +\Omega_{11}\left[\Omega_{21}+\Theta L_{1}\right] a_{1} b_{1}^{0}+\mu\left[c_{1 j}^{\prime} b_{1}-f_{1 j}^{\prime} s\right]
\end{aligned}
$$

\subsection{Revision of Farmers' Interest}

Having outlined an objective function of a manager who has a specific ecological interest in $\mathrm{BD}$, we can model bargains. The manager's skill should be to find compromises using appropriate interests, including ESS, in bargains. Interest functions of farmers have to be made compatible. How to do it? To make things simple we pursue land allocation (bargains) and additionally analyze labor contributions. Labor devoted to nature by farmers can be an additional bargain, here on suggestion for relaxation of land requests (for example, by small farmers who have abundant labor). Our property rights regime (statutory margins) recognizes labor (as give-and-take). For farmers devoting labor is not a loss. They can gain because less land is occupied. Laboring is a type of gifting for which a benefit, re-gifting (less land), can be expected which release pressure. It implies there is a claim on land as percentage, rights shift.

Then, in a bargain on "labor, land and money", new exchange options emerge which are determined by opposing interests. Individual contributions by farmers to eco-nets become negotiable with labor and compensation. We suggest that: (i) nature managers (as reeve) want labor and reduce compensation; he concedes some rights to land which are elements of the net. (ii) Since most farmers are land concerned, they hopefully see that their economic situation improves by conceding labor in exchange for land. However, anger will appear and power is needed. As stated, farmers may opt for bargaining (change rights) on field margins and want to minimize losses (by waivers on public land "b"). But then "costs and benefits" come into play, since they gain from "s". Interests must be corrected for gains from ESS, i.e. farmers must be convinced to be responsible for ESS provision as they benefit; again size of farmers may matter. Yet positions (power) depend on scarcity at the individual level; rights; collective bargaining options as well as running the scheme is built on the trust that managers succeed on contributions with all farmers. In the next section we analyze such a scenario.

\section{Modelling "Supply" and "Demand" for a Generic Social Optimum of ESS Provision}

To further explain a bargaining model that uses the above quadratic functions for the farm side, we must likewise include benefits from ESS. To do so, i.e. in a 
flexible modelling of farmers' sparing land for habitat, we again refer to the econet (landscape) as public. Now " $\mathrm{s}$ " is a service as public good. Lately, all farmers benefit from ESS, but provisions are regulated. Habitats are indirectly incentivized by "c". It means that we rely on a functional relationship between set-aside land and ESS reducing costs (interest: (28)). Taking into consideration that farmers firstly think they lose (are not compensated fully by payment), ESS provision might be objected; but benefits can be evaluated as reduced costs (pesticides, fertilizer, etc.). However ESS from the total net can encourage farmers to deliver landscape.

$$
\begin{aligned}
I_{i}^{u}= & p_{i}^{u}\left(1-b_{i}\right)+c_{c}\left[b_{i}-b^{c}\right]-f_{c} s-\gamma_{00}-w 1^{\prime} L_{i}^{\prime} 1-\gamma_{01} b_{i}+\gamma_{02 i} s_{c} \\
& +0.5 \cdot b_{i}^{\prime} \Gamma_{11 i} b_{i}-0.5 \cdot s_{c}^{\prime} \Gamma_{21 i} s_{c}+1^{\prime} L_{i} \Gamma_{32 i} s_{c}+b_{1}^{\prime} \Gamma_{31 i} s_{c}-b_{1}^{\prime} \Gamma_{41} r_{i}-b_{1}^{\prime} \Gamma_{51 i} r_{i}
\end{aligned}
$$

where: $w=$ wage

$$
f=\text { charge for ES service }
$$

Function (28) is the corresponding interest of farmers to interest of the manager (22'). It is a contingent interest based on ESS. The suggested compensation vehicle in our case is given as " $c$ " (now willingness to accept WTA) for a prescribed "b" (regulation). But additionally we included paying a fee to enable finance for ESS provision. We supplement the corresponding incentive (inflow of money in scheme as "c" for activities: supply) by recognition of benefits (demand) having a price " $\mathrm{f}$ "; i.e. a request for a fee (" $\mathrm{f}$ ", outflow of money; willingness to pay WTP for reduced costs). Note that " $c$ " is a compensation which has to be financed by a fee "f" (WTP) for ESS at management level. For farmers both, costs and benefits matter. (The net effect counts.) Compensation might be only for an extra " $b_{i}$ " beyond community regulation. So the construction of (28) works sequential and individual bargains keep other " $b_{j}$ "s constant. WTP shall become knowledgeable by calculating shadow prices for "s", though public. However, " $c$ " and " $f$ " are not part of the individual bargain; rather, " $b$ " and "L". Figures "s, $c$ and f" work at community level and shall be the same for all farmers to be set by the manager. Another point, the advantage of "b" as bargain instead of straight BD " $\mathrm{s}$ " is its visibility. Accordingly, we can model provision of "b" conditional to achieved "s" (constraint). Actually, taking a first derivative to $b$ is:

$$
b_{1 i}=\Omega_{11 i}^{*} q_{1 i}+\Omega_{12}^{*} L_{1 i} 1-\Omega_{13}^{*} c_{c 1}+\Omega_{14}^{*} S_{1 i}+\Omega_{14}^{*} X_{1 i}
$$

The background for the analysis is a farm behavioral depiction with preferred BD " $s$ " which implies "b" acceptance. By simulation (derivative to q) on the basis of individual

$$
b_{1 i}=\Omega_{12}^{* *} L_{1 i} 1-\Omega_{13}^{* *} C_{c 1}+\Omega_{14}^{* *} S_{1 i}+\Omega_{14}^{* *} X_{1 i}
$$

"p" (gross margins), we finally get a reduced form version of willingness to contribute " $b$ " on the basis of compensation (29') " $c$ " and " $s$ ". The job of ecological management is to assure " $\mathrm{s}$ " jointly. 


\subsection{Willingness to Contribute Land and Labor for Negotations}

For the ESS provision (collective action) "s" we need to add (combine efforts, i.e. field margins, etc.). Yet field margins are to be inserted and: $s_{1}=\Omega_{11}\left[\Omega_{21}+\Theta L_{1}\right] a_{1} b_{1}$ which gives:

$$
1-\left[\Omega_{11}\left[\Omega_{21}+\Theta L_{1}\right] a_{1} \Omega_{14}^{* *}\right] s_{1}=\Omega_{11}\left[\Omega_{21}+\Theta L_{1}\right] a_{1}\left[\Omega_{12}^{* *} L_{1} 1-\Omega_{13}^{* *} C_{c 1}+\Omega_{14}^{* *} X_{1}\right]
$$

And a reshuffle and approximation of labour for habitat interactions finally makes it:

$$
s_{1}=1-\left[\Omega_{11} \Omega_{21} a_{1} \Omega_{14}^{* *} s\right]^{-1} \Omega_{11}\left[\Omega_{21}+\Theta L_{1}\right] a_{1}\left[\Omega_{13}^{* *} c_{c 1}+\Omega_{14}^{* *} X_{1}\right]
$$

The modified encoding of the envisaged BD includes " $\mathrm{s}$ " dependent on all " $\mathrm{b}$ " as delivery in a new joint cost functions and provision of " $\mathrm{s}$ " at eco-net level can be achieved through a hybrid of regulation and incentives. Such depiction is interest driven; interactions of farmers are regulated by the ecological management. It enables the manager to predict an outline of an economic driven and $\mathrm{BD}$ based landscape. However the landscape is built on "individual farm and joint delivery elements"; ESSs are contingent on " $\mathrm{s}$ " as perception, and " $c$ " on compensation. We can get average $\hat{b}$ if one uses an averaging for participation.

$$
\widehat{b}=1 / n 1^{\prime} b_{1 i}=1 / n 1^{\prime} \Omega_{12}^{* *} L_{1 i} 1-1 / n\left[1^{\prime} \Omega_{13}^{* *}\right] c_{c 1}+\Omega_{14}^{* * *} S_{1 i}+\Omega_{14}^{* *} X_{1 i}
$$

An average field margin $\hat{b}$ can subsequently serve as reference in bargaining if it is constitutional. In negotiations a minimum provision of field margins is requested being referenced. We can work with altered rights structures in which PESs are paid to farmers as hybrid for additional effort. A way to solve the issue is to work with generic $\hat{s}$ and $\hat{b}$, and use bargaining for individual farms. Having a basis for a generic accord as necessary condition which reflects social cost-benefit-analysis (averages), bargaining is a sufficient condition of success.

\subsection{Willingness to Contribute Fees and Public Demand}

Note the issue is not pure control of efforts " $b$ " and free-riding on ESS "s"; rather, for cash requests of the manager from farmers: " $\mathrm{f}$ " per " $\mathrm{s}$ ". The manger now can assure farmers that he delivers "s" (as demand, WTP if the eco-net is established). Farmer objectives allow us to specify marginal values of benefits from "s", BD. By doing an optimization of land use by individual farms gives both potential fees and contingent optimization. The results are simulated demand functions (30) which are grasped from internal optimization (demand of "s"). Results are measured maximizations where $\mathrm{b}$ and $\mathrm{L}$ are constraints of incomplete compensation.

$$
\begin{gathered}
\partial I_{i}^{u} / \partial_{1} L_{i}=\gamma_{02 i}-\Gamma_{21 i} s_{c}+\Gamma_{32 i}^{\prime} 1 L_{i}+\Gamma_{31 i} b_{i}^{\prime}=\lambda_{s i}^{\prime} \\
\partial I_{i}^{u} / \partial_{1} b_{i}=c_{c}-p_{i}-\gamma_{01}+L_{i}^{\prime} \Gamma_{11 i} b_{i}+\Gamma_{31 i} S_{c}-\Gamma_{41} r_{i}=\lambda_{b i}^{\prime}
\end{gathered}
$$

Derivatives of Equations (30a and $b$ ) tell us how shadow prices for constraints 
and optimal choices are to be combined. In equations (30a and b) "b" and " $L$ " establish the shadow prices " $\lambda_{s i}$ " and " $\lambda_{b i}$ ". The optimization delivers us marginal value functions of the public good " $s$ " ("to be managed" as common property), i.e. for each farm $\mathrm{i}$ as dependent on individual contributions of " $\mathrm{b}$ " (request for "s"); shadow prices are firstly individual but contingent on CPR management. And they add vertically because we are confronted with a public good [42]. Any shadow price is a result [47] of a valuation of $\mathrm{BD}$ " $\mathrm{s}$ " which is a compromise, yet guaranteed. From economics of public goods it is pertinent that marginal functions add vertically; instead of private goods adding horizontally). For a reduced form version, similar to contingent valuation of species (indicator for ESS), $\lambda_{\mathrm{si}}$ is given at farm level:

$$
\gamma_{02 i}^{*}-\Gamma_{21 i}^{*} S_{c}+\Gamma_{32 i}^{\prime} 1 L_{i i}^{\prime}=\lambda_{s i}^{\prime}
$$

And adding the individual functions, in a next step, delivers the "landscape demand":

$$
\begin{gathered}
\sum_{i} \gamma_{02 i}^{*}-\sum_{i} \Gamma_{21 i}^{*} s_{c}+\sum_{i} \Gamma_{32 i}^{\prime} 1 L_{i i}^{\prime}=\sum_{i} \lambda_{s i} \\
\sum_{i} \lambda_{s i}=\lambda_{s}
\end{gathered}
$$

With this valuation, $\lambda_{s}$, the optimal price for " $\mathrm{s}$ " is accomplished at the community level (for $\Sigma \lambda_{\text {si }}$, here as a generic social welfare solution, i.e. without preference of the management). Dividing by the numbers of farmers (n) we also get the already mentioned average values. Equation (32) looks like a demand (function, but not added horizontally, rather vertically) and it delivers gross WTP as well as equates the WTP and WTA. Equations (31) and (32) could be seen as a virtual market demand for a social welfare optimization. It serves as a reference for public management; in fact we may deal with second best of bargaining. The logic should be that supply and demand can be separated and each farmer faces supply "b" and demand " $\mathrm{s";}$ but this is not realistic; rights are not distinct and farmers cannot be said to be either supplier or demander. So net-effects matter individually and the manager's task is to get information on typical farm exposures to costs and benefits of " $\mathrm{s}$ ". For the moment we are still within a group of farmers whose welfare is not including interest of the ecological management per se. To find a "socially optimal provision" of "s" (here as economically driven by cost-benefit) the functions are need to be recovered; the issue is what are farmers' preferred BD? Any given patterns of eco-nets at community must be simulated. Shadow prices are not always in balance, which then gives the financial resources fees, i.e. no caring for distributional effects.

Next, in our frame, any optimal "s" depends on labour, which means that the equilibrium is conditional. It also means that shadow prices for labour will leave individual farmers with different net positions. Further, recall that the ecological management may not be interested in the economic optimum of " $\mathrm{s}$ " (farmers' preference as demand on shadow prices), rather may pursue another (ecologically oriented) "s"; bargaining and budgeting, both serve cooperation. We need negotiations, because the "market solution" can be only a virtual solution, still it 
may guide behaviour. For negotiations it implies that landscape design and nature provision are to be embedded in a property rights regime which is justified against social welfare maximization. Vice versa, the social optimum is only a draft solution. It gives a first insight into compensation as we can get $\mathrm{c}$ and $\lambda_{\mathrm{s}}$ from knowledge of shadow price analysis for economic BD. At a practical level, for implementation of negotiations and bargain, references (average $s, b, c, \lambda_{s}$ ) tell the ecological management how deals can be anchored. Also, farmers recursively (in case of an agreed concession), have an initial orientation (an average habitat to be contributed and compensated). Then farms have the option to negotiate at the individual level.

\section{Issues, Reference and Property Rights for Bargaining}

For a further imbedding of the above CPR management structure in a bargaining model of the Harsanyi-Zusman type (explained before and [43]), let us come back to the need of giving reference scenarios based on simulations and look at participation. To substantiate a cooperative game, the non-cooperation option has to be modelled first. For an understanding, any option chosen depends on rights; so there is a right not to cooperate and the manager must come with contractual parameters which suit farmers. The manager shall have an entitlement to money (spending for WTA, and raising as WTP) and land rights for generic margins (no longer private), but not more. Two cases may be distinguished: (1) we work with current reality or (2) prescribe a "fair" institution based on averages (referenced to social optimum as generic). We commence with the second type. The argument is as follows: in many studies especially Bromley [48] there on common property) it is claimed that rights are proportionally set (equal rights in percentage of a generic duty to contribute land); this might be a key to regulate commons. So we need the public approval for this and individual bargaining starts then; on the other hand, as argued, we can bind the manager to a social optimum reference for a starting; but then he has to make individual contracts. Such starting is a general rule in the vein of Rawls referring to veil of ignorance. The specific issue is that ecologists as managers have own interest (already outlined), but the generic social optimum (above) is the mere minimum acceptance for duties. Ecological managers want to go beyond acceptance.

As stated, the crux is that ecologists' interests differs from farmers' on which parcel in an eco-net should receive priority (BD is important but for whom?). The suggested hybrid is a mix of rights. For the derivation of (endogenous) right based contribution to the eco-net (in a balanced start of ESS appreciation at community level, given the background from above) farmers need design support. Negotiations shall improve positions recursively as agreements are set on clearing trading rights. Then having received a WTA, which is organized by management, WTP for ESS can adjust at unit costs (for a vector of species BD agreed). Bargaining is multiple. For multiple bargaining, in that regard, the social optimum (thought generic) shall give a sense of an appropriate rights setting. 
This still allows non-cooperative results (farmers defect); but at risk of losing the contribution of other farmers. Non-cooperation is limited.

Nevertheless, the author is aware that property rights regimes determine bargaining positions, and at the same time, there is a need for legitimacy of rights. In that regard, following the pragmatic view of Bromley [49] that there will be a consensus on regulations; the attained equilibrium between farmers' needs for ESS and ecologist's optimum (BD as provision of a public good as suggested above) can hopefully substitute the conflict by insight in necessity.

As a further comment, farmers may seek independent BD provision as reference and might use this for individual bargaining; but with many small farms it is unrealistic. We cannot expect valuable BD achievable at a single farm; as a farmer might not pursue BD/ESS provision as single unit because of high costs, it is out of range. Farmers will ask for low community priced ESS (fees: $f$ ) and high compensation $(: \mathrm{c})$. BD provision is characterized by the public good aspect of ESS and the necessary eco-net. Only such a thing as a negotiation for joint ecology may pledge a valuation that can claim to be objective or reasonable (for reasonable as reference see the discourse philosophy of Rawls [48]. Then the duty is to deliver $\hat{b}$; but "you can negotiate or trading $\widehat{b}$ against labor". Another aspect is that search for BD will give us hopefully a wished BD. This (stable) BD depends on references (social one) and basic valuation of managers expresses a will for BD.

\section{Amendment of the Interest Function for Bargaining}

Applying the above qualifications to changes of farm objective functions (as based on new rights and modes of bargaining for getting trade-offs) options to work with references for bargaining appear. New bargaining options can be derived that qualify farm-management-bargaining as a deviation from a norm which is set as percentages of "b". Also, we newly quantify interest for labor as inclusion in optimization (34).

$$
\begin{aligned}
I_{1}^{c}= & p_{i}^{\prime} a_{i}\left(1-\Delta \mathbf{b}_{1}\right)+c_{1}^{r^{\prime}} a_{i} \Delta \mathbf{b}_{1}-\gamma_{011}^{\prime} a_{i} \Delta \mathbf{b}_{1}-\gamma_{021}^{\prime} \mathbf{s}_{1}-\gamma_{031}^{\prime} \Delta b_{1} \\
& +0.5 \cdot \Delta \mathbf{b}_{1}^{\prime} \Gamma_{11} \Delta \mathbf{b}+0.5 \cdot \mathbf{s}_{1}^{\prime} \Gamma_{21} \mathbf{s}_{1} \mathbf{1}-\Delta \mathbf{b}_{1}^{\prime} \Gamma_{41} \mathbf{s}_{1}-\Delta \mathbf{b}_{1}^{\prime} \Gamma_{51} \Delta \mathbf{l}_{1} \\
& -\Delta \mathbf{l}_{1} \Gamma_{61} \mathbf{s}_{1}-r_{1}^{\prime} \Gamma_{71} \Delta \mathbf{b}_{1}-r_{1}^{\prime} \Gamma_{81} \mathbf{s}_{1}-r_{1}^{\prime} \Gamma_{91} \Delta \mathbf{l}_{1}
\end{aligned}
$$

In case of an untamed management (below), labor offers may be better for an advance of ESS than land. Offers can be "musts". A "must" in (34) means management has no restriction in labor acquisition. In such specification farmers have the option to trade labor and land. BD provision is controlled through interactions with farmers, respectively. As the eco-management has been put into power by farmers, WTP and WTA come as money for provision; they matter marginally as margin change $\Delta \mathrm{b} \cdot \mathrm{c}$ and " $\mathrm{f}$ " is coming with $\lambda_{\mathrm{ei}}$; there is still a valuation. Shadow prices $\lambda_{\mathrm{ei}}$ are internal from the above specification (as uploaded lobbying function: 35 ). This characterizes a manager who can order contribution from farmers individually, though he must bargain for that. 


$$
\begin{aligned}
Z= & \lambda_{e 1}\left[\Omega_{11}\left[\Omega_{21}+\Theta L_{1}\right] a_{1} b_{1}^{c}+\Omega_{11}\left[\Omega_{21} a_{1} b_{1}\right]\right]-c_{1 j}^{\prime} \Delta b_{1} \\
& -\varphi_{10} \Delta b_{1}-0.5 \Delta b^{\prime} \Xi_{11} \Delta b_{1}+\lambda_{e 1} \Xi_{12} \Delta b_{1} \\
& +0.5 \lambda_{e 1}^{\prime} \Xi_{13} \lambda_{e 1}+\lambda_{e 1} \Xi_{14}\left[\Omega_{11}\left[\Omega_{21}+\Theta L_{1}\right] a_{1} \Delta b_{1}^{0}\right]-I_{1}^{r}
\end{aligned}
$$

Observed provision levels allow us to infer the underlying lobbying (power) functions that are specified here on basis of bilateral negotiations. Modelling the objective function can be synthesized using the weighting exercise, using iteration, revelation enables reconstruction, etc.

\section{Modelling of Property Rights Regimes}

\subsection{Untamed Manager (Leviathan)}

Now we merge objective functions of the managers and those of farmers by assigning each farmer a weight, related to their power [48]. In case of an "untamed Leviathan", the manager shall have full access to land also he needs labour (no limits). Farmers will calculate costs according to land and labour constraints. Modelling in that context means to optimize on behalf of management and group interest follows statutory regulations (as Leviathan), but in bargaining terms. I.e. we combine a political economy and principal-agent approach one can get numerical applications. With access land and labour, a manager has rights to demand them to get his objective "preservation", BD. He can regulate with no public limit on land use for field margins and labour and needs not to justify his $\mathrm{BD}$. The political economy model contains weights and we get:

$$
\begin{aligned}
\Pi_{1}^{L}= & {\left[\left(I-\omega_{1}\right) p_{1}\right]^{\prime}\left[\left(1-\mathbf{b}_{1}\right)+c_{1}^{r^{\prime}} a_{i} \Delta \mathbf{b}_{1}-f_{1}^{r^{\prime}} s\right.} \\
& -\left[\left[\left(I-\omega_{1}\right) \gamma_{011}\right]^{\prime}+\left[\left(I-\omega_{1}\right) \gamma_{021}\right]^{\prime} \Omega_{11}\left[\Omega_{21}+\omega_{1} \mathbf{L}_{11}+r_{1}^{\prime} \Gamma_{81}\right]-r_{1}^{\prime} \Gamma_{71}\right] \mathbf{b}_{1} \\
& -\left[\left(I-\omega_{1}\right) \gamma_{021}\right]^{\prime}\left[\mathbf{l}_{1}^{*}-\mathbf{L}_{11} 1\right]+0.5 \cdot\left[\left(I-\omega_{1}\right) \mathbf{b}_{1}\right] \Gamma_{11} \mathbf{b}_{1} \\
& +0.5 \cdot\left[\left(I-\omega_{1}\right)\left(\mathbf{l}_{1}^{*}-\mathbf{L}_{11} 1\right)\right]^{\prime} \Gamma_{31}\left[\mathbf{l}_{1}^{*}-\mathbf{L}_{11} 1\right] \\
& -\left[\left(I-\omega_{1}\right) \mathbf{b}_{1}\right]^{\prime} \Gamma_{51} \mathbf{L}_{11}\left[\mathbf{l}_{1}^{*}-\mathbf{L}_{11} 1\right]-\left[\left(I-\omega_{1}\right) r_{1}\right]^{\prime} \Gamma_{91}\left[\mathbf{l}_{1}^{*}-\mathbf{L}_{11} 1\right] b^{*} \\
& \left.+\lambda_{2}^{\prime}\left[1-\mathbf{b}_{1}\right] b^{*}\right]+\left[\lambda_{e 1}-\mu f_{1 j}^{\prime}-\lambda_{1 e} \Omega_{11}\right]\left[\Omega_{21}+\Theta L_{1}^{o}\right] a_{1} \mathbf{b}_{1} \\
& +\left[\Omega_{11}\left[\Omega_{21}+\Theta_{1} \mathbf{L}_{11}\right] a_{1} b_{1}^{0}\right]-c_{1 j}^{\prime} \mathbf{b}_{11}+\mu c_{1 j}^{\prime} \mathbf{b}_{1}
\end{aligned}
$$

where $\omega$ is a vector of weights on the diagonal $\left[\omega_{1}, \omega_{2}, \cdots, \omega_{n}\right]^{\prime}$ for power for farmers.

For result (37): derivatives of function (36) provide a system-wide expression of allocation

$$
\begin{aligned}
& \left(1-\omega_{1}\right)^{\prime}\left[p_{1}+c_{1}^{r^{\prime}} a_{i}-\gamma_{011}+\gamma_{021} \Theta_{1} \mathbf{L}_{11}+\Omega_{11} \Gamma_{81} r_{1}-\Gamma_{71} r_{1}^{\prime}+\Gamma_{11} \mathbf{b}_{1}+\Gamma_{51} \mathbf{L}_{11}-b^{*} I \lambda_{2}\right] \\
& +\left[\lambda_{e 1}-\mu f_{1 j}^{\prime}-\lambda_{1 e} \Omega_{11}\right]\left[\Omega_{21}+\Theta L_{1}^{o}\right] a_{1}-c_{1 j}^{\prime}+\mu c_{1 j}^{\prime}=0
\end{aligned}
$$




$$
\begin{aligned}
& \left(1-\omega_{1}\right)^{\prime}\left[\gamma_{021} \Theta_{1} \mathbf{b}_{1}-\gamma_{021}+\Gamma_{31}\left[\mathbf{l}_{1}^{*}-\mathbf{L}_{11}\right]-\left[\left(1+\Phi_{1}\right) \Gamma_{51} \mathbf{b}_{1}+\Gamma_{91} b^{*} r_{1}\right]\right] \\
& +\Omega_{11}\left[\Omega_{21}+\Theta_{1}\right] a_{1} b_{1}^{0}=0 \\
& {\left[1-\mathbf{b}_{1}\right] b^{*}=0}
\end{aligned}
$$

Again, optimal Ls reflect a situation where the manager has full power to regulate land use and rights to procure labour. Condition (37) also provides shadow prices for labour procured, but sets no limits on farm outputs. It is not a social optimum; rather weights are endogenous and give negotiation power. Species evaluation is endogenous, yet it works after iteration.

\subsection{Tamed Manager}

The previous presentation of a political economy (untamed manager) was built on the assumptions of control on land and labour for the eco-net. But if a labour market exists between regions, the manager has no control over labour (he can ask straight; but rather he has to be aware that labour migration implies equating of shadow prices between communities which in an exchange system creates competition. If equating shadow price for labour is carried out on a competitive basis, optimization has to reconsider that prices become market driven. Any modelling of this aspect has to rethink control and allocation of labour within a group. So far, we have assumed that farmers are short term oriented and bargain with a manager on land and labour to improve ESS, and that ESS is a common for the community. The function is now:

$$
\begin{aligned}
\Pi_{1}^{L} & =\left[\left(I-\omega_{1}\right) p_{1}\right]^{\prime}\left[\left(1-\mathbf{b}_{1}\right)+c_{1}^{r^{\prime}} a_{i} \Delta \mathbf{b}_{1}-f_{1}^{r^{\prime}} s\right. \\
& -\left[\left[\left(I-\omega_{1}\right) \gamma_{011}\right]^{\prime}+\left[\left(I-\omega_{1}\right) \gamma_{021}\right]^{\prime} \Omega_{11}\left[\Omega_{21}+\omega_{1} \mathbf{L}_{11}+r_{1}^{\prime} \Gamma_{81}\right]-r_{1}^{\prime} \Gamma_{71}\right] \mathbf{b}_{1} \\
& -\left[\left(I-\omega_{1}\right) \gamma_{021}\right]^{\prime}\left[\mathbf{l}_{1}^{*}-\mathbf{L}_{11} 1\right]+0.5 \cdot\left[\left(I-\omega_{1}\right) \mathbf{b}_{1}\right] \Gamma_{11} \mathbf{b}_{1} \\
& +0.5 \cdot\left[\left(I-\omega_{1}\right)\left(\mathbf{l}_{1}^{*}-\mathbf{L}_{11} 1\right)\right]^{\prime} \Gamma_{31}\left[\mathbf{l}_{1}^{*}-\mathbf{L}_{11} 1\right] \\
& -\left[\left(I-\omega_{1}\right) \mathbf{b}_{1}\right]^{\prime} \Gamma_{51} \mathbf{L}_{11}\left[\mathbf{l}_{1}^{*}-\mathbf{L}_{11} 1\right]-\left[\left(I-\omega_{1}\right) r_{1}\right]^{\prime} \Gamma_{91}\left[\mathbf{l}_{1}^{*}-\mathbf{L}_{11} 1\right] b^{*} \\
& \left.+\lambda_{2}^{\prime}\left[1-\mathbf{b}_{1}\right] b^{*}\right]+\lambda_{1}\left[l-1^{\prime}\left[\mathbf{l}_{1}^{*}-\mathbf{L}_{11} 1\right]\right] \\
& +\left[\lambda_{e 1}-\mu f_{1 j}^{\prime}-\lambda_{1 e} \Omega_{11}\right]\left[\Omega_{21}+\Theta L_{1}^{o}\right] a_{1} \mathbf{b}_{1} \\
& +\left[\Omega_{11}\left[\Omega_{21}+\Theta_{1} \mathbf{L}_{11}\right] a_{1} b_{1}^{0}\right]-c_{1 j}^{\prime} \mathbf{b}_{11}+\mu c_{1 j}^{\prime} \mathbf{b}_{1}
\end{aligned}
$$

In this context taming of a Leviathan Manager means a relaxation on the notion of full labour access (bargained within a farmer group); instead, a limit on labour exchange at a market for a shadow price prevails. Shadow prices between communities are considered market prices for labor, and farmers know prices in the neighborhood. Hence their bargaining power increases. In presentation (38) the manager treats labor different from that of (37). The tamed total labor (under control but issued from farmers) is yet price dependent. Since a shadow 
price is calculated, this value can be used in individual bargains. The BD delivery depends on labor L as agreed. But in tamed bargaining, shadow prices are subject to a market driven exchange. Farmers decide on labor bought and sold according to prices prevailing between communities; in dealing with neighboring communities, shadow prices become relevant. The manager changes his bargains with farmers on labor for eco-nets (BD), which recursively means altered BD.

In fact, by taming the manager (Leviathan) farmers look at equalizing shadow prices, and if returns become too low in a community, labor prevalence (access) is reduced. The manger has less access. Contributions to the eco-net are subject to bargaining competing with migration. We can put new weights in front of the revenue minus cost as components for the interest of farmers. The same applies to ecological objectives. Any value-added from farming is dependent on rights regimes. At the moment, no movement (leaving group: sell farm) is allowed for land. The feat of staging a tamed Leviathan over an untamed Leviathan can be seen in an explicit recognition of labor as a corrective for behavior of the CPR management. Labor valuation is most crucial for mobility and determination of shadow prices for resource believed by farmers. Technically, the problem can be solved by taking derivatives as below:

$$
\begin{aligned}
\left(1-\omega_{1}\right)^{\prime}[ & \left.p_{1}+c_{1}^{r^{\prime}} a_{i}-\gamma_{011}+\gamma_{021} \Theta_{1} \mathbf{L}_{11}+\Omega_{11} \Gamma_{81} r_{1}-\Gamma_{71} r_{1}^{\prime}+\Gamma_{11} \mathbf{b}_{1}+\Gamma_{51} \mathbf{L}_{11}-b^{*} I \lambda_{2}\right] \\
+\left[\lambda_{e 1}-\mu\right. & \left.f_{1 j}^{\prime}-\lambda_{1 e} \Omega_{11}\right]\left[\Omega_{21}+\Theta L_{1}^{o}\right] a_{1}-c_{1 j}^{\prime}+\mu c_{1 j}^{\prime}-b^{*} I \lambda_{2}=0 \\
& \left(1-\omega_{1}\right)^{\prime}\left[\gamma_{021} \Theta_{1} \mathbf{b}_{1}-\gamma_{021}+\Gamma_{31}\left[\mathbf{l}_{1}^{*}-\mathbf{L}_{11}\right]-\left[\left(1+\Phi_{1}\right) \Gamma_{51} \mathbf{b}_{1}+\Gamma_{91} b^{*} r_{1}\right]\right] \\
& +\Omega_{11}\left[\Omega_{21}+\Theta_{1}\right] a_{1} b_{1}^{0}+\lambda_{1}=0 \\
& {\left[1-I \mathbf{b}_{1}\right] b^{*}=0 } \\
& l-1^{\prime}\left[\mathbf{l}_{1}-\mathbf{L}_{11} 1\right]=0
\end{aligned}
$$

To solve for labor costs (equalize shadow prices) in extended modelling is requested to have a similar optimization for a second community and link communities; i.e. linking by having migration and same shadow prices. Shadow prices for labor are determined by interactions between communities and labors $l_{1}$ and $l_{2}$ add up to total labor: $l_{1}+l_{2}=l_{t}$. Total labor is a system anchor. Individual bargains can be modelled by taking one farmer and keep others constant.

\section{Summary}

In this contribution, institutional aspects of ESS provision were discussed with respect to spatial ESS provision in a landscape for habitats (ecological nets or main structure EMS). In the scheme, field margins and farm related nature elements are subject to direct vs. indirect control of public management. We suggested a hybrid of institutions in which payments for eco-system services PES are private and econ-net management for EMS is public. A public manager has authority to individually bargain with land users on contracts for an EMS (econet) introduced. To avoid the tragedy of the commons, we have made sug- 
gestions on how to derive interest functions of farmers who want to minimize both, sparing land and working for nature; though they benefit from the public good ESS. A public manager has power to impose statutory regulations on field margin provision and land. However, he pursues also "interest" in terms of a special biodiversity $\mathrm{BD}$ which is modelled. The achieved $\mathrm{BD}$ is dependent on right setting which is nothing but taming a manager who would otherwise pursue his interest. This interest is explicitly modelled. Yet the manager is not impartial. He is considered an "ecologist" who maximizes setting aside of land and pursues his interest for a specific $\mathrm{BD}$, he wants. The interest functions are put into a framework of political economy bargaining as applied to common property management of ESS.

\section{References}

[1] Kleijn, D., Baquero, R.A., Clough, Y., Diaz, M., De Esteban, J., Fernandez, F., Gabriel, D., Herzog, F., Holzschuh, A., Johl, R., Knop, E., Kruess, A., Marshall, E.J.P., Steffan-Dewenter, I., Tscharntke, T., Verhulst, J., West, T.M. and Yela, J.L. (2006) Mixed Biodiversity Benefits of Agri-Environment Schemes in Five European Countries. Ecology Letters, 9, 243-254. https://doi.org/10.1111/j.1461-0248.2005.00869.x

[2] Hanley, N., Banerjee, S., Lennox, G.D. and Armsworth, P.R. (2012) How Should We Incentivize Private Landowners to "Produce" More Biodiversity? Oxford Review of Economic Policy, 228, 93-113. https://doi.org/10.1093/oxrep/grs002

[3] Bamière, L., David, M. and Vermont, B. (2013) Agri-Environmental Policies for Biodiversity When the Spatial Pattern of the Reserve Matters. Ecological Economics, 85, 97-104. https://doi.org/10.1016/j.ecolecon.2012.11.004

[4] Mettepeningen, E., Beckmann, V. and Eggers, J. (2011) Public Transaction Costs of Agri-Environmental Schemes and their Determinants-Analysing Stakeholder Involvement and Perceptions. Ecological Economics, 70-81.

[5] Scherr, S. and McNeely, J.A. (2008) Biodiversity Conservation and Agricultural Sustainability: Towards a New Paradigm of "Eco-Agriculture" Landscapes. Philosophical Transactions of the Royal Society B, 363, 477-494. https://doi.org/10.1098/rstb.2007.2165

[6] Hanley, N., Acs, S., Dallimer, M., Gaston, K.J., Graves, A., Morris, J. and Armsworth, P.R. (2012) Farmscale Ecological and Economic Impacts of Agricultural Change in the Uplands. Land Use Policy, 29, 587-597. https://doi.org/10.1016/j.landusepol.2011.10.001

[7] Nuppenau, E.-A. (2014) Integrated Modelling of Payment for Ecosystem Services: Using Willingness to Pay and Accept, for Nature Provision and Addressing Public Management in Cultural Landscape. Operational Research, 14, 151-175. https://doi.org/10.1007/s12351-014-0150-0

[8] Runge, C.F. and Defrancesco, E. (2006) Exclusion, Inclusion, and Enclosure: Historical Commons and Modern Intellectual Property. World Development, 34, 1713 1727. https://doi.org/10.1016/j.worlddev.2006.02.002

[9] Packhurst, C., Kivi, P., Donner, J. and Smith, R.B.W. (2002) Agglomeration Bonus: An Incentive Mechanism to Re-Unit Fragmented Habitats for Biodiversity Conservation. Ecological Economics, 41, 305-328. https://doi.org/10.1016/S0921-8009(02)00036-8

[10] Packhurst, G.M. and Shogren, J.F. (2007) Spatial Incentives to Coordinate Conti- 
guous Habitat. Ecological Economics, 64, 344-456.

https://doi.org/10.1016/j.ecolecon.2007.07.009

[11] Durant, R., Younbg-Pyoung, C., Byungseob, K., KIM and Seongjong, L. (2004) Paradigm for Environmental and Natural Resource Management in the $21^{\text {st }}$ Century. Administration and Society, January 2004, 35, 643-682.

[12] Hodge, I.D. and Willima, M.A. (2012) Neoliberalism, Rural Land Trusts and Institutional Blending. Geoforum, 43, 472-482. https://doi.org/10.1016/j.geoforum.2011.11.007

[13] Jones, P.J.S. (2013) Governing Protected Areas to Fulfil Biodiversity Conservation Obligations: From Habermasian Ideals to a More Instrumental Reality. Environment, Development and Sustainability, 15, 39-50. https://doi.org/10.1007/s10668-012-9375-3

[14] Rauscher, M. (1998) Leviathan and Competition among Jurisdictions: The Case of Benefit Taxation. Journal of Urban Economics, 44, 59-67. https://doi.org/10.1006/juec.1997.2060

[15] Araral, E. (2014) Ostrom, Hardin and the Commons: A Critical Appreciation and a Revisionist View. Environmental Science \& Policy, 36, 11-23. https://doi.org/10.1016/j.envsci.2013.07.011

[16] Brunckhorst, D.J. (2005) Integration Research for Shaping Sustainable Regional Landscapes. Journal of Research Practice, 1, Article M7. http://jrp.icaap.org/index.php/jrp/article/view/16/35

[17] Rauscher, M. (2000) Interjurisdictional Competition and Publich Sector Prodigalty: The Triumphe of the Market over the Sate. Finanzarchiv, 57, 89-105. https://doi.org/10.1628/0015221014006224

[18] Defrancesco, E., Gatto, P., Runge, F.S. and Trestini, S. (2007) Factors Affecting Farmers' Participation in Agri-Environmental Measures: A Northern Italian Perspective. Journal of Agricultural Economics, 59, 114-131. https://doi.org/10.1111/j.1477-9552.2007.00134.x

[19] Vanberg, V. (2000) Globalization, Democracy, and Citizens' Sovereignty: Can Competition among Governments Enhance Democracy? Constitutional Political Economy, 11, 87-112. https://doi.org/10.1023/A:1009026301486

[20] Rauscher, M. (2005) Economic Growth and Tax-Competing Leviathans. International Tax and Public Finance, 12, 457-474. https://doi.org/10.1007/s10797-005-1834-4

[21] Rauscher, M. (2007) Tax Competition, Capital Mobility and Innovation in the Public Sector. German Economic Review, 8, 28-40. https://doi.org/10.1111/j.1468-0475.2007.00132.x

[22] Oskam, A. and Slangen, L. (1998) The Financial and Economic Consequences of a Wildlife Development and Conservation Plan: A Case-Study for the Ecological Main Structure in the Netherlands. In: Dabbert, S., Dubgaard, A., Slangen, L. and Whitby, M., Eds., The Economics of Landscape and Wildlife Conservation, 113-133.

[23] Cooke, B. and Moon, K. (2015) Methodological and Ideological Options Aligning "Public Good" Environmental Stewardship with the Landscape-Scale: Adapting MBIs for Private Land Conservation Policy. Ecological Economics, 114, 152-158. https://doi.org/10.1016/j.ecolecon.2015.03.027

[24] Wossink, A., Jurgens, C. and van Wenum, J. (1998) Optimal Allocation of Wildlife conservation Areas within Agricultural Land. In: Dabbert, S., Dubgaard, Al., Slangen, L. and Whithby, M., Eds., The Economics of Landscape and Wildlife Conser- 
vation, Wallingford, 205-216.

[25] Perfecto, I. and Vandermeer, J. (2007) Agroecological Matrix as Alternative to the Sparing/Agricultural Intensification Model. PNAS, 107, 5786-5791.

https://doi.org/10.1073/pnas.0905455107

[26] Perfecto, I., Vandermeer, J. and Wright, A. (2009) Nature's Matrix. Linking Agriculture, Conservation and Food Sovereignty. Sterling.

[27] McCairns, J. (2004) Eco-Ethical Issues: Self-Regulating versus Subsidized Ecosystems. International Journal of Sustainable Development \& World Ecology, 11, 36-47. https://doi.org/10.1080/13504500409469809

[28] Hanna, S.S., Folke, C. and Mäler, K.-G., Eds. (1996) Rights to Nature. Ecological, Economic, Cultural and Political Principles of Institutions for the Environment. Washington DC.

[29] Dauber, J., Purtauf, T., Allspach, A., Frisch, J., Voigtländer, K. and Wolters, V. (2005) Local vs. Landscape Controls on Diversity: A Test Using Surface-Dwelling Soil Macroinvertebrates of Differing Mobility. Global Ecology and Biogeography, 14, 213-221. https://doi.org/10.1111/j.1466-822X.2005.00150.x

[30] Fohrer, N., Möller, D. and Steiner, N. (2002) An Interdisciplinary Modelling Approach to Evaluate the Effects of Land Use Systems. Physics and Chemistry of the Earth, 27, 655-662. https://doi.org/10.1016/S1474-7065(02)00050-5

[31] Perfecto, I. and Vandermeer, J. (2006) The Agricultural Matrix and a Future Paradigm for Conservation. Conservation Biology, 21, 274-277.

[32] Wossink, A., von Wenum, J., Jurgens, C. and de Snoo, G. (1999) Co-Ordinating Economic, Behavioural and Spatial Aspects of Wildlife Preservation in Agriculture. European Review of Agricultural Economics, 26, 443-460.

[33] Nuppenau, E.-A. and Helmer, M. (2004) Biodiversity Management through Compensation Payments forLandscape Elements: On Spatial Aspects in Bio-Economic Modelling to Get Cost Effectiveness. Sixth Annual BioEcoWorkshop at King's College Cambridge, 2-3 September 2004.

[34] Lankoski, J. and Ollikainen, M. (2003) Agri-Environmental Externalities: A Framework for Designing Targeted Policies. European Review of Agricultural Econonmics, 30, 51-75. https://doi.org/10.1093/erae/30.1.51

[35] Meffe, G.K., Nielsen, L.A., Knight, R.L. and Schenborn, D.A. (2007) Ecosystem Management: Adaptive, Community-Based Conservation. Washington DC.

[36] de Groot, R.S., Alemade, R., Braat, L., Hein, L. and Willemen, L. (2010) Challenges in Integrating the Concept of Ecosystem Services and Values in Landscape Planning, Management and Decision Making. Ecological Complexity, 3, 260-272. https://doi.org/10.1016/j.ecocom.2009.10.006

[37] Harsanyi, J.C. (1993) A Simplified Bargaining Model for the N-Person Cooperative Game. International Economic Review, 4, 194-220. https://doi.org/10.2307/2525487

[38] Hashimoto, S., Nakamura, S., Saito, O., Kohsaka, R., Kamiyama, C., Tomiyoshi, M. and Kishioka, T. (2014) Mapping and Characterizing Ecosystem Services of Social-Ecological Production Landscapes: Case Study of Noto. Japan Sustainability Science, 9, 431-438.

[39] Röhm, O. and Dabbert, S. (1999) Modelling Regional Production and Income. In: Huylenbrook, G.V. and Withby, M., Eds., Countryside Stewardship: Farmers, Policies and Markets, Amsterdam, 113-133.

[40] Lankoski, J., Lichtenberg, E. and Ollikainen, M. (2008) Point/Nonpoint Pollution Effluent Trading with Spatial Heterogeneity. American Journal of Agricultural 
Economics, 90, 1044-1058. https://doi.org/10.1111/j.1467-8276.2008.01172.x

[41] Theil, H. (1971) Principles of Econometrics. New York.

[42] Zusman, P. (1976) The Incorporation and Measurement of Social Power in Economic Models. International Economic Review, 17, 447-462. https://doi.org/10.2307/2525712

[43] Rausser, G. and Zusman, P. (1992) Public Policy: Explanations and Constitutional Prescriptions. American Journal of Agricultural Economics, 74, 247-257. https://doi.org/10.2307/1242479

[44] Cambers, R. (1988) Applied Production Economics: A Dual Approach. Cambridge.

[45] Paris, Q. and Howitt, R.E. (2001) The Multi-Output and Multi-Input Symmetric Positive Equilibrium Problem. In: Heckelei, T., Witzke, H.P. and Henrichsmeyer, W., Eds., Agricultural Sector Modelling and Policy Information Systems, 88-100.

[46] Golan, M., Judge, G.G. and Miller, D. (1996) Maximum Entropy. Wiley, Somerset.

[47] Mitchell, R.C. and Carson, R.T. (1989) Using Surveys to Value Public Goods, the CV Method. Washington. International Economic Review, 4, 194-220.

[48] Rawls, J. (2000) Lectures on the History of Moral Philosophy. Cambridge, MA.

[49] Bromley, D. (2006) Sufficient Reason: Volitional Pragmatism and the Meaning of Economic Institutions. Princeton.

Submit or recommend next manuscript to SCIRP and we will provide best service for you:

Accepting pre-submission inquiries through Email, Facebook, LinkedIn, Twitter, etc. A wide selection of journals (inclusive of 9 subjects, more than 200 journals) Providing 24-hour high-quality service User-friendly online submission system Fair and swift peer-review system Efficient typesetting and proofreading procedure Display of the result of downloads and visits, as well as the number of cited articles Maximum dissemination of your research work

Submit your manuscript at: http://papersubmission.scirp.org/

Or contact nr@scirp.org 